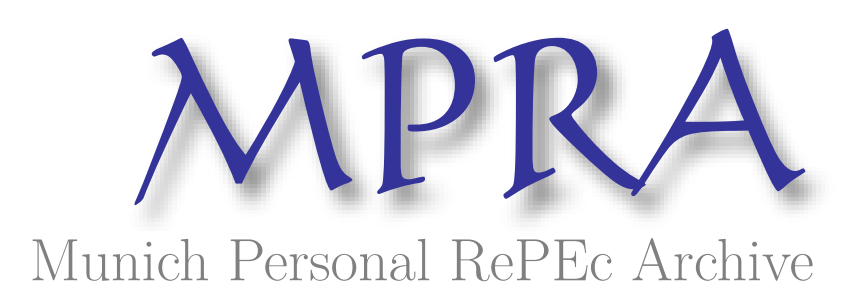

\title{
Maternal Smoking, Misclassification, and Infant Health
}

Brachet, Tanguy

2008

Online at https://mpra.ub.uni-muenchen.de/21466/

MPRA Paper No. 21466, posted 19 Mar 2010 22:42 UTC 


\title{
Maternal Smoking, Misclassification, and Infant Health
}

\author{
Tanguy Brachet
}

\begin{abstract}
When a binary variable is misclassified, the measurement error is necessarily negatively correlated with the truth. Consequently, linear instrumental variable methods that treat it as endogenous deliver inflated causal estimates, resulting from attenuated first stage coefficients. In this paper, I propose an approach based on parametric methods for misclassified binary dependent variables that recovers consistent estimates of the second stage coefficients. I then re-analyze the relationship between infant health and maternal smoking. Conventional IV estimates deliver implausibly large birth weight losses among African Americans. Accounting for misclassification yields estimates that are considerably smaller in magnitude and more consistent with experimental evidence.
\end{abstract}

Keywords: Misclassification, prenatal maternal smoking, birth outcomes JEL classification: C30; I12

\footnotetext{
${ }^{0}$ I thank Peter Adams, Ken Chay, Laura Chioda, Bryan Graham, Sally Kwak, David Lee, Alex Mas, Paco Martorell, Stephen Raphael, Heather Royer and am especially endebted to David Card and Jim Powell for their encouragement and for numerous suggestions. I also thank Francesca Cornaglia for providing prenatal maternal smoking statistics from the Health Survey of England. All errors are my own.

Address: Center for Outcomes Research, University of Pennsylvania School of Medicine, 3535 Market St, Suite 1029, Philadelphia, PA 19104. Email: brachet@mail.med.upenn.edu.
} 


\section{Introduction}

Perhaps motivated by the extensive and robust evidence on the responsiveness of smoking to prices and taxes, policy makers have increasingly turned to higher excise taxes on cigarettes as an effective policy instrument to reduce smoking. ${ }^{1}$ As observed by Lien and Evans [2005], there have been 113 state-level tax increases between 1990 and 2003. The impact of these tax changes can be expected to be heterogeneous, as differences in price elasticity by race, gender, age, and income groups have been documented by many, including Lewit and Coate [1982], Chaloupka and Wechsler [1997], Farrelly and Bray [1998], Ringel and Evans [2001].

One particularly important group of smokers is pregnant women, because prenatal maternal smoking is thought to have adverse effects on the health of infants. It is hypothesized that tobacco use during pregnancy causes delayed conception and infertility, ectopic pregnancy, ${ }^{2}$ placental abruption, ${ }^{3}$ premature delivery and intrauterine growth retardation (and, thus, low birth weight), sudden infant death syndrome, and a host of other adverse maternal and infant outcomes (see Ananth, Savitz, and Luther [1996], Floyd, Zahniser, Gunter, and Kendrick [1991], Anderson, Bland, and Peacock [1992], Ness, Grisso, and Hirschinger [1999], Surgeon General [2001]). The mechanisms by which the toxic chemicals in cigarettes produce adverse fetal effects are not precisely known. Carbon monoxide, however, is known to affect oxygen transfer to the placenta, and nicotine in known to constrict the uterine arteries, also resulting in oxygen deprivation ("hypoxia") (Lambers and Clark [1996]). Regarding the relationship between smoking during pregnancy and birth, a 2001 report on Women and Smoking by the Surgeon General concludes:

\footnotetext{
${ }^{1} \mathrm{~A}$ more cynical view, one often echoed in the press, holds that cigarette taxes serve politicians as an effective means of filling state coffers during budgetary crises (e.g. Piccinini [2005]).

${ }^{2}$ Ectopic pregnancy results from theimplantation of a fertilized ovum outside the uterus, usually in the fallopian tubes.

${ }^{3}$ Placental abruption is theearly separation of a normal placenta from the wall of the uterus.
} 
"The risk for perinatal mortality-both stillbirth and neonatal deaths-and the risk for sudden infant death syndrome (SIDS) are increased among the offspring of women who smoke during pregnancy. Infants born to women who smoke during pregnancy have a lower average birth weight and are more likely to be small for gestational age than infants born to women who do not smoke. [...] Low birth weight is associated with increased risk for neonatal, perinatal, and infant morbidity and mortality. The longer the mother smokes during pregnancy, the greater the effect on the infant's birth weight."

With these adverse effects in mind, this paper utilizes data from U.S. birth certificates, which were standardized in 1989 to ask about the mother's smoking habits during pregnancy, to estimate the causal effect of smoking on infant health. Unfortunately, the prenatal tobacco use question posed on birth certificates is coarse and vague, and, even in the absence of ambiguity, it is quite likely that some mothers might fail to respond truthfully given the significant stigma associated with smoking during pregnancy. As I show in this paper, the misclassification error associated with self-reported prenatal tobacco use is considerable and has nontrivial consequences for estimating the causal effect of maternal smoking on birth outcomes. ${ }^{4}$ Indeed, in the presence misclassification, the OLS estimator is typically biased towards zero (Aigner [1973], Jakubson [1986], Bollinger [1996], Black, Berger, and Scott [2000], Bound, Brown, and Mathiowetz [2001], Frazis and Loewenstein [2003]). On the other hand, the OLS estimator may be biased upwards in magnitude by correlations between the propensity of mothers to smoke and unobserved factors that also affect their children's health. Recognizing the latter complication, previous researchers have proposed using cigarette prices and/or taxes as instruments for maternal smoking (e.g. Rosenzweig and Schultz [1983], Evans and Ringel [1999], Lien and Evans [2005]).

\footnotetext{
${ }^{4}$ In this sense, this study follows the spirit of the literatures on the returns to schooling, when years of schooling is mismeasured (e.g. Kane, Rouse, and Staiger [1999]), and on the union wage effect when union status is misreported (e.g. Freeman [1984], Jakubson [1986], Card [1996]). Methodologically, it is closely related to Poterba and Summers [1995], who are concerned with flows in and out of employment and in and out of the labor force when these are reported with error.
} 
While the effect of measurement error in the dependent variable on OLS estimates is well known, much less attention has been paid to its effects in an instrumental variables (IV) estimation framework. Failure to correct for misclassification in an endogenous binary variable leads to attenuated first stage coefficient estimates and, by extension, to inflated second stage parameter estimates. This observation provides an explanation for the unexpected result from previous studies that the IV estimates often exceed their OLS counterparts in magnitude, in some cases by substantial amounts (e.g. Evans and Ringel [1999], Lien and Evans [2005]). To solve this problem, I exploit the recent parametric methods of Hausman, Abrevaya, and Scott-Morton [1998] that allow for misclassification in self-reported smoking status among pregnant women, thereby delivering consistent estimates of the causal effect of prenatal maternal smoking on infant health. Assuming a simple model of misclassification, I am able to recover the conditional probability that a mother is truly a smoker (i.e., the distribution of the true latent treatment variable), as well as estimates of the misclassification probabilities. I find that roughly 30 percent of smoking mothers are misclassified as non-smokers ("false negatives"), implying that conventional, linear IV estimates of the effect of maternal smoking on birth outcomes are inflated by 43 percent. In addition, I find significant heterogeneity in misclassification rates and smoking patterns by race, education, and geographic region.

A particularly dramatic illustration of the impact of misclassification arises for African American women in southern states. ${ }^{5}$ For this group, the linear IV model delivers an estimated effect of maternal tobacco use on birth weight of $-1,338$ grams, an implausible magnitude considering that an infant born to a mother in this group weighs on average 3,131 grams at birth. Applying the methodology developed in this paper reduces the estimated effect to -206 grams, which is much closer in magnitude to the effect for whites.

The remainder of the paper is organized as follows. Section 2 provides a brief review of both the economic and epidemiological literatures on the relationship between prenatal maternal smoking and infant health, drawing attention to epidemiologists' concerns about the accuracy of

\footnotetext{
${ }^{5}$ Here, the South consists of Alabama, Florida, Georgia, Louisiana, Mississippi, and South Carolina.
} 
pregnant mothers' self-reported smoking status. Section 3 describes the econometric problem and the identification strategy. Section 4 provides details on the data employed, and is followed by results in Section 5. Section 6 concludes.

\section{Background}

While there is general agreement on the nocive effects of maternal smoking, the magnitudes of these effects remain a matter of continuing study. In their survey of randomized and quasi-randomized trials of smoking cessation programs implemented during pregnancy, Lumley, Oliver, Chamberlain, and Oakley [2004] report a broad range of maternal smoking-birth weight effects (see Table 1 of the Appendix).

As with the majority of the estimates from the epidemiological literature, however, these are "intent to treat" estimates and don't account for the fact that not all mothers in the treatment group quit smoking, nor do all mothers in the control group continue to smoke during their pregnancy. In recognition of this problem, however, Permut and Hebel [1989] invoke the econometrics literature and provide the first causal estimate of maternal smoking on birth weight by re-examining Sexton and Hebel [1984]'s experimental data. Using random assignment into Sexton and Hebel [1984]'s extensive smoking cessation program as an instrument for smoking behavior, they calculate an IV estimate of -430 grams. This figure provides a useful benchmark for my estimates.

The broad range of estimates reported in Table 1 provides some insight into why epidemiologists remain drawn to this question. The studies featured in the table meet the strictest of requirements for inclusion in the meta-analyses of the Cochrane Reviews and therefore represent a small fraction of the effort to estimate the prenatal maternal smoking-birth weight effect. Adding to the confusion, the vast non-experimental epidemiological literature generates estimates ranging from the thousands of grams to zero.

One of the important contributions of the epidemiological literature, however, has been the recognition that pregnant mothers misreport their true smoking status. Many studies therefore address this obstacle by directly measuring the main biological markers of smoking. In particular, 
one can assess an individual's smoking status (and, some would argue, smoking intensity) by measuring the concentration of nicotine's main metabolite, cotinine, in serum, saliva, or urine. ${ }^{6}$ Based on a given cutoff for this marker (usually between 5 and $25 \mu \mathrm{g} / \mathrm{l}$ ), one can re-classify self-reported non-smokers as smokers (and vice versa), and evaluate the smoking-birth weight relationships directly and relatively free of error, measuring birth weight effects, for instance, in terms of lost grams per $\mu g / l$ of cotinine.

The evidence on the accuracy of pregnant women's self-reported smoking status is mixed. From a sample of rural, pregnant women, Britton, Brinthaupt, Stehleand, and James [2004] report a 35 percent false negative rate and a 10 percent false positive rate. ${ }^{7}$ Conversely, Klebanoff, Levine, Clemens, DerSimonian, and Wilkins [1998] find that 95 percent of women who denied smoking and 87 percent of women who stated that they smoked reported their status accurately.

However, in a sample of 74 women who enrolled in prenatal care at four publicly funded clinical cites, Webb, Boyd, Messina, and Windsor [2003] find that 73 percent self-reported nonsmokers had urine cotinine values greater than $80 \mathrm{ng} / \mathrm{ml}$ and 48 percent had values exceeding $100 \mathrm{ng} / \mathrm{ml}$, whereas true non-smokers generally have urine cotinine concentrations below $20 \mathrm{ng} / \mathrm{ml}$.

Among studies that measure discrepancies between self-reports and serum or saliva cotinine concentrations, Boyd, Windsor, Perkins, and Lowe [1998] report false negative and false positive rates of 14 and 26 percent, respectively. Bardy, Seppälä, Lillsunde, Kataja, Koskela, Pikkarainen, and Hiilesmaa [1993] find that of the self-reported smokers, 38\% were nonsmokers and $3.4 \%$ of the self-reported non-smokers were smokers.

The recognition that self-reports might be noisy measures of the truth has only recently filtered into the economics literature on smoking (e.g. Adda and Cornaglia [2006], Abrevaya [2006]). In

\footnotetext{
${ }^{6}$ As a by-product, this technology has also given rise to a large literature on the accuracy of pregnant women's self-reported smoking status.

${ }^{7}$ The false negative rate is the probability that a mother self-reports to be a non-smoker given that she truly smokes. Conversely, the false positive rate is the probability that a mother declares herself to be a smoker given that she truly doesn't smoke.
} 
particular, up to this point, causal estimates of prenatal maternal smoking on infant outcomes in the economics literature have been based exclusively on self-reported tobacco use data, such as those available from birth certificates or from the NLSY.

For instance, using birth records covering all births in the United States between 1989 and 1992, Evans and Ringel [1999] use state-level cigarette excise taxes as an instrument for smoking during pregnancy, providing the first evidence that prenatal maternal smoking is responsive to cigarette taxes. Their estimates of the causal effect of prenatal smoking on infant birth weight are between 350 and 600 grams, considerably above the OLS estimates which generally lie somewhere between 200 and 250 grams. Given that the parameter of interest is identified from relatively infrequent changes in state cigarette taxes, Lien and Evans [2005] use the same data but propose to focus only on those states that enacted large cigarette tax increases over the 1990-1997 period and comparing birth outcomes to similar states. Their estimate then drops to 189 grams, a figure that is comparable to the within-mother fixed effect estimate of Abrevaya [2006], who constructs a matched panel of mothers from the Natality Detail over the period 1990 to 1998.

\subsection{Misreporting in Birth Records}

Several epidemiological studies have attempted to assess the accuracy of information recorded in birth records, including Buescher, Taylor, Davis, and Bowling [1993], Piper, Mitchel, Snowden, Hall, Adams, and Taylor [1993], Reichman and Hade [2001], Roohan, Josberger, Acar, Dabir, Feder, and Gagliano [2003], Zollinger, Przybylski, and Gamache [2005]. Such studies typically match and compare birth certificate records to some "gold standard" data set, for instance hospital of birth medical records. While these analyses differ in terms of "gold standard" data sets, they consistently find that demographic characteristics, delivery methods, and (certain) birth outcomes are well reported on birth certificates. For instance, comparing the birth records of a random sample of women in North Carolina to their medical records at the delivery hospital, Buescher, Taylor, Davis, and Bowling [1993] find extremely accurate self-reports of birth weight, Apgar score, and delivery method. However, the match rates for tobacco use, alcohol use, obstetric procedures, 
and events during labor and delivery are $84 \%, 56 \%, 69 \%$, and 62\%, respectively. ${ }^{8}$ Collectively, these studies call into question the quality and accuracy of self-reported information on birth certificates, particularly tobacco use. ${ }^{9}$

\subsection{Smoking Participation vs. Smoking Intensity}

Most studies of smoking behavior at the micro level implement some version of a two-part model of consumption whereby participation is modeled separately from intensity to account for the numerous zeroes that are observed in the data (Cragg [1971], Atkinson, Gomulka, and Stern [1984], Jones [1989]). The present analysis differs in that I focus exclusively on the smoking participation decision and ignore smoking intensity, as typically measured by the number of cigarettes smoked per day. The motivation is twofold.

The first is pragmatic and recognizes the imperfect nature of birth records. As described in Section 4, the participation variable is self-reported smoking status during pregnancy, while the intensity variable is the number of cigarettes smoked per day, conditional on first self-reporting to be a smoker. Yet I argue that self-reported smoking status is likely to be subject to considerable misclassification (particularly false negatives), either as a result of misunderstanding induced by ambiguity in the birth certificate's smoking question (see Section 4.1) or of stigma associated with prenatal smoking. The econometric approach in this paper attempts to overcome the biases induced by these miscategorizations. Addressing the measurement error in the number of cigarettes smoked per day (including the error first induced by misclassified smoking status) would require a much richer model and is beyond the scope of this paper.

Second, while smoking intensity is typically measured by the number of cigarettes smoked per

\footnotetext{
${ }^{8}$ Likewise, using data from the HealthStart program in New Jersey, Reichman and Hade [2001] find that prenatal care use is over-reported, while alcohol and tobacco use were considerably under-reported.

${ }^{9}$ In the empirical analysis, this will motivate estimating models that are as parsimonious as possible, so as to avoid further biases due to misreporting in other controls.
} 
day, both the economics and epidemiological literatures have shown it to be a poor metric. For example, two studies from the economics literature have documented that, when controlling for prices faced by smokers, the number of cigarettes smoked is a poor (if not irrelevant) proxy for actual tobacco consumption. Using data on the brands and quantities of cigarettes smoked, Evans and Farrelly [1998] find that smokers substitute into longer, higher tar, higher nicotine content cigarettes when faced with higher per-pack taxes. As a result, while smokers consume fewer cigarettes in response to higher taxes, they actually increase their nicotine and tar intake. This evidence calls into question the degree to which the number of cigarettes smoked reflects actual smoking intensity. Adda and Cornaglia [2006] reach a similar conclusion using data on serum or saliva cotinine concentrations from the National Health and Nutrition Examination Survey (NHANES) and Health Survey of England (HSE). Their work provides more direct evidence that the number of cigarettes smoked is a poor measure of smoking intensity (i.e. has little power in predicting cotinine levels). In the epidemiological literature, Boyd, Windsor, Perkins, and Lowe [1998] confirm the Adda and Cornaglia [2006] finding that the number of cigarettes smoked per day

is only mildly correlated with saliva cotinine levels among pregnant women. Similar conclusions are drawn in England, Kendrick, Gargiullo, Zahniser, and Hannon [2001].

\subsection{Effects of Taxes on Smoking}

Interest in the economics of smoking and public policy towards tobacco has surged in the past quarter-century. Early views of cigarette smoking and other addictive behaviors held that they were irrational and that the apparatus of conventional economics was ill-suited to their analysis (see Elster [1979], Winston [1980], among others). In particular, the demand for cigarettes was thought not to conform to basic principles of economics, including the law of demand. However, a now substantial body of empirical research has refuted this view, demonstrating that cigarette demand is (robustly) responsive to prices, and other broad measures included in the "full price" of smoking. In their exhaustive review of the literature, Chaloupka and Warner [2000] settle on a consensus estimate of the elasticity of cigarette demand around -0.4. Based largely on this figure, for instance, Cutler, Gruber, Hartman, Landrum, Newhouse, and Rosenthal [2002] forecasted 
that the 1998 Master Settlement Agreement (MSA) between 46 states and the major US tobacco manufacturers would induce an 11 to $13 \%$ drop in smoking rates, $90 \%$ of which they estimate would be due to higher prices, the remaining $10 \%$ coming from tobacco counter-advertising campaigns. ${ }^{10}$

In the tobacco sector, excise taxes levied by federal, state, and local governments represent a significant component of the price of cigarettes. A substantial literature has documented that when excise taxes increase, they are passed onto consumer prices more than one for one. Harris [1987], for instance, estimates that the eight cent federal tax increase of 1983 led to a 17-cent increase in consumer prices. The more conservative estimate of Keeler, Hu, Barnett, and Manning [1993] is that a one cent tax increase raises retail prices by 1.11 cents. $^{11}$

With such an uncommon pass-through to consumer prices in mind, Evans, Ringel, and Stech [1999] argue that tobacco research should focus on taxes, which are directly manipulable by policy, rather than prices. In empirical applications that adhere to this recommendation, however, the pass-through is a critical parameter in elasticity calculations since, as detailed in Evans and Ringel [1999], the demand elasticity is given by $\varepsilon_{d}=\frac{\partial S}{\partial P} \frac{\bar{P}}{\bar{S}}=\left(\frac{\partial S}{\partial T a x} / \frac{\partial P}{\partial T a x}\right) \frac{\bar{P}}{\bar{S}}$, where $S$ is some measure of smoking, and $P$ and Tax are the price and excise tax on cigarettes, respectively. The term $\frac{\partial P}{\partial T a x}$ represents the pass-through from taxes to retail prices. In a regression of average state cigarette prices on excise taxes and a full set of state and year fixed effects, I estimate a pass-through of 1.19, which is in the upper tail of estimates, ${ }^{12}$ although comparable to Evans and Ringel [1999]'s 1.15. To be conservative, in the elasticity calculations below, I adopt a unit pass-through, as in Ringel and Evans [2001] and Lien and Evans [2005].

\footnotetext{
${ }^{10}$ According to the MSA, the major US tobacco companies agreed to pay the states roughly $\$ 87$ billion (in present value terms) through 2025 to compensate for health care expenses incurred by Medicaid.

${ }^{11}$ Becker, Grossman, and Murphy [1994] argue that the reason cigarette excise taxes are passed through more than one for one lies in the interaction between the commodity's addictive nature and the industry's concentrated market structure.

${ }^{12}$ See Evans, Ringel, and Stech [1999] and Chaloupka and Warner [2000].
} 


\subsection{Effects of Taxes on Maternal Smoking and Birth Outcomes}

\subsubsection{Taxes and Prenatal Maternal Smoking}

Because smokers respond to prices and taxes, recent studies have tried to pin down the causal effect of smoking on birth weight by instrumenting for smoking behavior using state and federal cigarette excise taxes. Evans and Ringel [1999] were the first to document the (perhaps surprising) fact that pregnant women are responsive to excise taxes. Using data from the US Natality Detail from 1989 to $1992,{ }^{13}$ they provide evidence that smoking prevalence is significantly negatively correlated with state cigarette taxes, with an estimated elasticity of -0.5, though smoking intensity (conditional on smoking) is not. Adding three more years of data, Ringel and Evans [2001] report an overall participation elasticity near -0.7 . This estimate, however, masks considerable heterogeneity by race/ethnicity, age, marital status, and level of education with, for instance, the demand by unmarried pregnant women being relatively price inelastic $\left(\hat{\varepsilon}_{\text {Particip. }}=-0.37\right)$, and that of college graduates being extremely elastic $\left(\hat{\varepsilon}_{\text {Particip. }}=-3.39\right)$. Using virtually identical data, but first aggregating to state-by-month cells, Gruber and Köszegi [2001] and Gruber and Zinman [2001] estimate prenatal smoking participation elasticities of -0.35 for pregnant women and -0.38 for pregnant teenagers. With data from the National Maternal and Infant Health Survey of 1988 and its 1991 follow-up, Bradford [2003] finds a similar -0.35 participation elasticity among pregnant women.

In an important clarification, Colman, Grossman, and Joyce [2003] address whether the relationship between state excise taxes and the prevalence of smoking during pregnancy is a response by pregnant women, or whether it reflects the response of women of reproductive age. With information on the prevalence of smoking at multiple points in time, they are able to analyze the relationship between taxes and prenatal quits and postpartum relapses. They find that smokers are indeed induced to quit during pregnancy when faced with higher cigarette taxes, estimating a

\footnotetext{
${ }^{13}$ The US Natality Detail is a census of all births occurring within the United States and contains detailed characteristics about the mother and about the infant's health, as well as information on prenatal tobacco use. See Section 4.1.
} 
quitting elasticity of about 1 .

\subsubsection{Prenatal Maternal Smoking and Birth Outcomes}

Since excise taxes are arguably exogenous to birth outcomes, Evans and Ringel [1999] exploit them as instruments for smoking behavior, yielding a statistically significant 300-600 gram gap in birth weight between smokers and non-smokers. ${ }^{14}$ Their IV estimates, however, are not statistically distinguishable from their OLS counterparts of around -250 grams.

In a follow-up article, Lien and Evans [2005] focus on four states that experienced large excise tax increases in the 1990's and employ a matching technique to find states that appear similar to these treatment states before they experienced the large tax hike. Their method delivers slightly smaller estimates of the effect of smoking on birth weight ( -182 grams) than their OLS counterparts. As a result, both Evans and Ringel [1999] and Lien and Evans [2005] conclude that the omitted variables problem may not be too serious. This paper, however, argues that the proximity of OLS and IV estimates additionally reflects a downward bias in the OLS estimate and an upward bias in the IV estimates due to misclassified smoking status in birth records.

Almond, Chay, and Lee [2005] and Torelli [2000] estimate the effect of smoking on birth weight by matching on mothers' propensity scores, and find a roughly 200 gram difference between smokers and non-smokers. Torelli [2000] also finds that there is considerable heterogeneity in parameter estimates when he splits his sample by race/ethnicity. An illustration of this phenomenon is provided in Table 2 of the Appendix. Using the same sample as Evans and Ringel [1999], I re-estimate their first stage equations of smoking behavior on federal plus state excise taxes first pooling across all racial and ethnic groups, and then interacting the tax variable with race/ethnicity indicators. Whereas the pooled tax effect on smoking participation is between -0.037 and -0.024 , interacting with race/ethnicity produces the perverse result that African Americans smoke more in the face of higher taxes, rather than less. When the relationships are estimated separately by race/ethnicity,

\footnotetext{
${ }^{14}$ Inference in Evans and Ringel [1999] may be compromised, however, since their standard errors are not clustered by state $\times$ month, which is the only dimension along which there is variation in their instrument.
} 
more meaningful estimates are restored. Pooling the effects of mother characteristics and state and time fixed effects across racial/ethnic groups appears to be causing these perverse results. Therefore, in what follows, all analyses are performed separately by race/ethnicity, an approach also favored by Kai and Poirier [2001].

\section{Econometric Framework}

The parameter of interest is the causal effect, $\gamma$, of prenatal maternal smoking on some outcome, $Y_{i}$, which, for concreteness, I will assume is birth weight. Assuming a linear model,

$$
Y_{i}=\gamma S_{i}^{*}+\mathbf{X}_{i}^{\prime} \boldsymbol{\beta}+u_{i}
$$

where $S_{i}^{*}$ is mother $i$ 's true smoking status, $\mathbf{X}_{i}$ is a vector of her characteristics, and $u_{i}$ is unobservable.

At least two problems arise in estimating $\gamma$. First, OLS estimation of (1) is likely subject to omitted variables bias. Mothers who smoke may be more likely to drink, have poor nutrition, or engage in other unobservable behaviors detrimental to birth weight. As such, one might expect $S_{i}^{*}$ to be negatively correlated with $u_{i}$, yielding an OLS estimate of $\gamma$ that overstates its true magnitude. The extant economics literature on maternal smoking has so far focused on this problem.

Second, a mother's true smoking status may be unobserved, with a surrogate, $S_{i}$, being observed in its stead. $S_{i}$ might differ from $S_{i}^{*}$ because of recording error, ambiguity in the smoking question on the birth certificate, or intentional misreporting. While misreporting of smoking status among pregnant women has received considerable attention in the clinical literature, the economics literature has largely ignored the problem. As discussed below, ignoring misclassification can generate considerable biases in both first and second stage estimates.

To address the problem of omitted variables, previous authors such as Rosenzweig and Schultz [1983], Evans and Ringel [1999], and Lien and Evans [2005] have modeled a mother's decision to 
smoke by:

$$
S_{i}^{*}=\mathbf{1}\left(\mathbf{Z}_{i}^{\prime} \mathbf{\Pi}+v_{i}>0\right)
$$

where $\mathbf{Z}_{i}$ is a vector of exogenous variables that includes $\mathbf{X}_{i}$ as well as additional instruments that are unrelated to $u_{i}$ (these are generally either cigarette prices or excise taxes). In this model, the omitted variables problem is captured by non-zero correlation between $u_{i}$ and $v_{i}$. In the absence of misclassification of smoking status and assuming that $v_{i}$ is uniformly distributed, the two-stage least squares estimator is consistent for $\gamma$.

Now suppose that self-reported smoking status, $S_{i}$, is an imperfect measure of true smoking status, $S_{i}^{*}$, and that the probabilities of misclassification depend only on a mother's true smoking status, but are otherwise independent of $\mathbf{Z}_{i}$. In particular, suppose the misclassification probabilities are

$$
\begin{aligned}
& \alpha_{0} \equiv \operatorname{Pr}\left(S_{i}=1 \mid S_{i}^{*}=0\right)=\operatorname{Pr}\left(S_{i}=1 \mid S_{i}^{*}=0, \mathbf{Z}_{i}\right) \\
& \alpha_{1} \equiv \operatorname{Pr}\left(S_{i}=0 \mid S_{i}^{*}=1\right)=\operatorname{Pr}\left(S_{i}=0 \mid S_{i}^{*}=1, \mathbf{Z}_{i}\right)
\end{aligned}
$$

where the second equalities on each line reflect the assumption that misclassification probabilities are unrelated to other covariates conditional on true smoking status. As pointed out by Kane, Rouse, and Staiger [1999], these assumptions on the misclassification process are the dichotomous variable analogs of the classical measurement error assumptions for continuous variables in that they assume no association between misclassification probabilities and observables. ${ }^{15}$ It is straightforward to derive the following expression for the conditional expectation of the observed

\footnotetext{
${ }^{15}$ Aigner [1973] first considered a model similar to this one, though he was more precisely concerned with the effects of misclassification of an (exogenous) binary regressor, rather than of an outcome variable. Following the work of Kane, Rouse, and Staiger [1999] and Black, Berger, and Scott [2000], Frazis and Loewenstein [2003] propose a GMM procedure to recover consistent estimates of $\gamma$ and $\beta$ in (1), when $S_{i}^{*}$ is uncorrelated with unobservables. They also provide an expression for the inconsistency of the OLS estimator of $\gamma$ in a regression of $Y_{i}$ on $X_{i}$ and $S_{i}$, which I exploit in the empirical analysis to present "corrected" OLS estimates of $\gamma$, and which is reproduced in Appendix Section A.1.
} 
dependent variable:

$$
\begin{aligned}
\mathbb{E}\left(S_{i} \mid \mathbf{Z}_{i}\right) & =\operatorname{Pr}\left(S_{i}=1 \mid \mathbf{Z}_{i}\right) \\
& =\alpha_{0}+\left(1-\alpha_{0}-\alpha_{1}\right) \operatorname{Pr}\left(S_{i}^{*}=1 \mid \mathbf{Z}_{i}\right) \\
& =\alpha_{0}+\left(1-\alpha_{0}-\alpha_{1}\right) F_{v}\left(\mathbf{Z}_{i}^{\prime} \mathbf{\Pi}\right)
\end{aligned}
$$

where $F_{v}(\cdot)$ denotes the $c d f$ of $v .^{16}$

\subsection{Parametric Identification}

Under the assumption that $F_{v}$ is known, Hausman, Abrevaya, and Scott-Morton [1998] consider the parametric identification of the parameters in (3). They point out that (3) provides a moment condition based upon which one can estimate $\left(\alpha_{0}, \alpha_{1}, \boldsymbol{\Pi}^{\prime}\right)^{\prime}$. For example, using nonlinear least squares, one can minimize

$$
N^{-1} \sum_{i}\left[S_{i}-\left(a_{0}+\left(1-a_{0}-a_{1}\right) F_{v}\left(\mathbf{Z}_{i}^{\prime} \mathbf{P}\right)\right)\right]^{2}
$$

over $\left(a_{0}, a_{1}, \mathbf{P}^{\prime}\right)$. Alternatively, $\left(\alpha_{0}, \alpha_{1}, \boldsymbol{\Pi}^{\prime}\right)^{\prime}$ can be estimated by maximum likelihood, where the log-likelihood function is given by:

$$
\begin{aligned}
\mathcal{L}\left(a_{0}, a_{1}, \mathbf{P}^{\prime}\right)= & N^{-1} \sum_{i}\left[S_{i} \ln \left(a_{0}+\left(1-a_{0}-a_{1}\right) F_{v}\left(\mathbf{Z}_{i}^{\prime} \mathbf{P}\right)\right)\right. \\
& \left.+\left(1-S_{i}\right) \ln \left(1-a_{0}-\left(1-a_{0}-a_{1}\right) F_{v}\left(\mathbf{Z}_{i}^{\prime} \mathbf{P}\right)\right)\right]
\end{aligned}
$$

In the empirical work below, I adopt the latter approach.

Conditions for identification of $\left(\alpha_{0}, \alpha_{1}, \boldsymbol{\Pi}^{\prime}\right)^{\prime}$ are similar to those for the traditional binary choice model. The only additional requirement is that the noise not be so severe as to overwhelm the signal. Specifically, identification requires $\alpha_{0}+\alpha_{1}<1$, a condition that Hausman,

\footnotetext{
${ }^{16}$ Note that this expression collapses to the usual $F_{v}\left(\mathbf{Z}_{i}^{\prime} \mathbf{\Pi}\right)$ when there is no misclassification.
} 
Abrevaya, and Scott-Morton [1998] term the "Monotonicity Condition," since it guarantees that $\alpha_{0}+\left(1-\alpha_{0}-\alpha_{1}\right) F_{v}(c)$ is strictly increasing in $c$ if $F_{v}$ is strictly increasing. ${ }^{17}$

The model parameters are identified entirely from the nonlinearity of $F_{v} \cdot{ }^{18}$ Although all parameters are parametrically identified, it is useful to discuss the intuition behind semi-parametric identification of the misclassification probabilities. In particular, if the distribution of $v_{i}$ were unknown, identification of the misclassification probabilities would require considerable richness in the support of the index $\mathbf{Z}_{i}^{\prime} \boldsymbol{\Pi}$. This can be seen by evaluating the limit of $\mathbb{E}\left(S_{i} \mid \mathbf{Z}_{i}\right)$ when the single index tends to $-\infty$ and $+\infty$ in expression (3):

$$
\lim _{\mathbf{Z}_{i}^{\prime} \Pi \rightarrow-\infty} \mathbb{E}\left(S_{i} \mid \mathbf{Z}_{i}\right)=\alpha_{0} \quad \text { and } \quad \lim _{\mathbf{Z}_{i}^{\prime} \boldsymbol{\Pi} \rightarrow+\infty} \mathbb{E}\left(S_{i} \mid \mathbf{Z}_{i}\right)=1-\alpha_{1}
$$

In other words, although they are not the objects of interest per se, credible identification of the misclassification probabilities, $\alpha_{0}$ and $\alpha_{1}$, requires that the single index get reasonably large in magnitude, so as to push $\operatorname{Pr}\left(S_{i}^{*}=1 \mid \mathbf{Z}_{i}\right)$ close 0 and 1 for some $i$. The intuition behind this necessity is that by assuming that misclassification rates are constant and depend only on the true value of $S^{*}$, the probability of false positives, $\alpha_{0}$, is identified from the group of individuals associated with a near zero probability of truly being smokers. These are individuals for whom $\mathbf{Z}_{i}^{\prime} \mathbf{\Pi}$ is highly negative and who are therefore very unlikely to be smokers. But, because a constant proportion $\alpha_{0}$ are misclassified as smokers, $\operatorname{Pr}\left(S_{i}=1 \mid \mathbf{Z}_{i}\right)$ never falls below $\alpha_{0}$ no matter how negative $\mathbf{Z}_{i}^{\prime} \boldsymbol{\Pi}$ gets. Likewise, the probability of false negatives, $\alpha_{1}$, is estimated from the group of individuals who are almost surely smokers (large $\mathbf{Z}_{i}^{\prime} \mathbf{\Pi}$ ) but classify themselves as non-smokers. For this reason, the conditional probability of self-classifying as a smoker, $\operatorname{Pr}\left(S_{i}=1 \mid \mathbf{Z}_{i}\right)$, never rises above $1-\alpha_{1}$. These observations are illustrated in the Figure 1, which plots the CDF of a logistically distributed random variable measured without (solid line) and with (dashed line)

\footnotetext{
${ }^{17}$ In the absence of the Monotonicity Condition, but still assuming $\alpha_{0}+\alpha_{1} \neq 1$, the magnitude of $\Pi$ is identified, while its sign is not.

${ }^{18}$ Hausman, Abrevaya, and Scott-Morton [1998] briefly allude to this.
} 
error. The figure is drawn assuming that false positives occur at a rate of $\alpha_{0}=0.05$, and false negatives at a rate of $\alpha_{1}=0.30$. As is clear, the dashed line asymptotes to $\alpha_{0}$ (rather than to zero) in the left tail, and to $1-\alpha_{1}$ (rather than to 1 ) in the right tail.

Expression (3) highlights the critical role played by the nonlinearity of $F_{v}$ in identifying all model parameters. As an illustration, consider the linear probability model, for which $F_{v}(c)=c$. Then,

$$
\begin{aligned}
\mathbb{E}\left(S_{i} \mid \mathbf{Z}_{i}\right) & =\alpha_{0}+\left(1-\alpha_{0}-\alpha_{1}\right)\left(\mathbf{Z}_{i}^{\prime} \boldsymbol{\Pi}\right) \\
& =\left(\alpha_{0}+\pi_{0}\right)+\mathbf{Z}_{1 i}^{\prime}\left[\left(1-\alpha_{0}-\alpha_{1}\right) \boldsymbol{\Pi}_{1}\right]
\end{aligned}
$$

where $\mathbf{Z}=\left(1, \mathbf{Z}_{1}^{\prime}\right)^{\prime}$ and $\boldsymbol{\Pi}=\left(\pi_{0}, \boldsymbol{\Pi}_{1}^{\prime}\right)^{\prime}$. Expression (5) illustrates that none of the parameters in the model are separately identified, and that OLS estimates of $\boldsymbol{\Pi}_{1}$ will be attenuated in the presence of misclassification. ${ }^{19}$

\subsection{Implications for Linear IV}

The preceding discussion of identification in the linear probability model sheds light on the inconsistencies generated by misclassification in the linear IV model. Suppose we ignore misclassification and have at our disposal one instrument, $Z_{i}$, so that $\gamma$ is just identified. Then the linear IV estimator for $\gamma$ is the ratio of the reduced form to the first stage estimators:

$$
\hat{\gamma}_{J I I V}=\frac{\widehat{\gamma \Pi_{R F}}}{\widehat{\Pi_{F S}}}
$$

where $\hat{\gamma}_{J I I V}$ is the just-identified IV estimator, and $\widehat{\gamma \Pi_{R F}}$ and $\widehat{\Pi_{F S}}$ are the estimated coefficients on $Z_{i}$ in the regressions of $Y_{i}$ on $Z_{i}$ (i.e. the reduced form) and $S_{i}$ on $Z_{i}$ (i.e. the first stage), respectively. Assuming that $Z_{i}$ is a valid instrument for $S_{i}^{*}$ and is appropriately excluded from the structural equation (1), the reduced form estimator $\widehat{\gamma \Pi_{R F}}$ is unbiased and consistent. However, as

\footnotetext{
${ }^{19}$ Hausman, Abrevaya, and Scott-Morton [1998] and Neuhaus [1999] show that this result is not restricted to the linear probability model: parameter estimates are also attenuated for general $F_{v}(\cdot)$ if misclassification is ignored.
} 
shown above, if the first stage dependent variable is subject to misclassification $\left(\operatorname{Pr}\left(S_{i} \neq S_{i}^{*}\right)>0\right)$, then $\widehat{\Pi_{F S}}$ is inconsistent and biased towards zero by a factor of $\left(1-\alpha_{0}-\alpha_{1}\right)$ :

$$
\widehat{\Pi_{F S}} \stackrel{p}{\longrightarrow}\left(1-\alpha_{0}-\alpha_{1}\right) \Pi
$$

Therefore,

$$
\begin{aligned}
\hat{\gamma}_{J I I V} \stackrel{p}{\longrightarrow} \frac{p \lim \widehat{\gamma \Pi_{R F}}}{p \lim \widehat{\Pi_{F S}}} & =\frac{\gamma \Pi}{\left(1-\alpha_{0}-\alpha_{1}\right) \Pi} \\
& =\frac{1}{\left(1-\alpha_{0}-\alpha_{1}\right)} \gamma
\end{aligned}
$$

so that $|\gamma|<\left|p \lim \hat{\gamma}_{J I I V}\right|$ assuming $0<\alpha_{0}+\alpha_{1}<1$. As such, the two-stage least squares estimator of $\gamma$ is inconsistent and overstates the magnitude of the truth by a factor of $\left(1-\alpha_{0}-\alpha_{1}\right)^{-1}$.

\subsection{A Two-Step GMM Procedure}

While linear IV does not deliver consistent estimates of $\gamma$, expression (3) for the conditional expectation of the observed smoking status suggests a procedure that does. It rests on the observation that the probability of being a self-reported smoker depends on the misclassification rates and the probability of truly being a smoker, only.

By making distributional assumptions on the unobservable $v_{i}$ (excluding the Uniform), estimating $\left(\alpha_{0}, \alpha_{1}, \boldsymbol{\Pi}^{\prime}\right)^{\prime}$ by maximizing the log-likelihood (4) delivers consistent estimates of $\boldsymbol{\Pi}$, and thus of the probability of truly being a smoker. This implies that a proxy for $S_{i}^{*}$ in (1) can be constructed that is purged of both misclassification and its correlatedness with the structural error, $u_{i}$, namely $F_{v}\left(\mathbf{Z}_{i}^{\prime} \hat{\mathbf{\Pi}}\right)$.

The two-step procedure I propose is as follows:

1. Assuming a particular distribution for $v_{i}$, estimate $\left(\alpha_{0}, \alpha_{1}, \boldsymbol{\Pi}^{\prime}\right)^{\prime}$ by maximum likelihood, and construct the fitted probabilities that mother $i$ is truly a smoker, $F_{v}\left(\mathbf{Z}_{i}^{\prime} \hat{\mathbf{\Pi}}\right)$.

2. Estimate (1) by OLS, substituting $F_{v}\left(\mathbf{Z}_{i}^{\prime} \hat{\mathbf{\Pi}}\right)$ for $S^{*}$. The resulting estimator of $\gamma$ is consistent assuming correct specification of functional forms, i.e. of the distribution of unobservables. 
Standard errors for the resulting estimator are delivered by viewing this sequential procedure as a method of moments problem, as detailed by Newey [1984] and Newey and McFadden [1994].

\subsection{Consistency}

The main drawback of the approach described in section 3.3 is its reliance on unverifiable parametric assumptions. In particular, consistency of the estimator of $\gamma$ rests entirely on the assumption of correct specification of the conditional distribution of truly being a smoker. To see this, consider a simpler model without covariates, in which the one dichotomous explanatory variable is properly measured but correlated with the error term:

$$
Y_{i}=\gamma S_{i}^{*}+u_{i}
$$

In the empirical work below, I estimate models in which, for instance, $E\left[S_{i}^{*} \mid Z_{i}\right]=\Lambda\left(Z_{i}^{\prime} \Pi\right)$, where $\Lambda(\cdot)$ is the $c d f$ of the logistic distribution, i.e. in which $v_{i}$ is assumed to be logistically distributed.

The second stage of the GMM procedure regresses $Y_{i}$ on $\Lambda\left(Z_{i}^{\prime} \hat{\Pi}\right)$, which amounts to assuming and exploiting the following moment condition:

$$
E\left\{\Lambda\left(Z_{i}^{\prime} \Pi\right) \times\left[Y_{i}-\gamma \Lambda\left(Z_{i}^{\prime} \Pi\right)\right]\right\}=0
$$

This equality holds exclusively if the conditional mean of $S_{i}^{*}$ is properly specified since

$$
\begin{aligned}
E\left\{\Lambda\left(Z_{i}^{\prime} \Pi\right) \times\left[Y_{i}-\gamma \Lambda\left(Z_{i}^{\prime} \Pi\right)\right]\right\} & =E_{Z}\left\{\Lambda\left(Z_{i}^{\prime} \Pi\right) \times\left[E\left(Y_{i} \mid Z_{i}\right)-\gamma \Lambda\left(Z_{i}^{\prime} \Pi\right)\right]\right\} \\
& =E_{Z}\left\{\Lambda\left(Z_{i}^{\prime} \Pi\right) \times\left[\gamma E\left(S_{i}^{*} \mid Z_{i}\right)-\gamma \Lambda\left(Z_{i}^{\prime} \Pi\right)\right]\right\} \\
& =0 \text { as long as } E\left(S_{i}^{*} \mid Z_{i}\right)=\Lambda\left(Z_{i}^{\prime} \Pi\right)
\end{aligned}
$$

where the second line follows from the assumption that $E\left[u_{i} \mid Z_{i}\right]=0$.

In the empirical implementation, both probits and logits are estimated to assess the sensitivity of the estimates to specification of the conditional distribution of $v_{i}$. However, this is admittedly a relatively weak test given how similar the logistic and standard normal $c d f$ s are in shape. 
Another possible shortcoming is the assumption that the misclassification rates, $\alpha_{0}$ and $\alpha_{1}$, are independent of covariates, conditional on $S_{i}^{*}$. While this assumption delivers a parsimonious framework, some flexibility is worth pursuing given the rigid requirements governing consistency in the second stage. Indeed, in Section 5, I provide some evidence that this assumption is violated.

\subsection{External Information on $\alpha_{0}$ and $\alpha_{1}$}

In Section 2, I alluded to the vast epidemiological literature assessing the discrepancies between self-reported tobacco use among pregnant women and true smoking status. One might therefore consider exploiting these external estimates of $\alpha_{0}$ and $\alpha_{1}$. Unfortunately, as discussed in Section 2, there is little consensus on the degree of misreporting among pregnant women. Further, these studies tend to be relatively small in scale and concentrate on specific subpopulations. As a result, any estimate from this literature is likely to suffer from external validity problems, with each figure being conditional on the circumstances of the study. This observation makes it difficult credibly to calibrate $\alpha_{0}$ and $\alpha_{1}$ to the context of the Natality Detail. ${ }^{20}$

Nonetheless, I have explored this option, albeit with little success. In the U.S., the National Health and Nutrition Examination Survey III, 1988-1994 (NHANES III) collects data not only from questionnaires, but also from the administration of various medical examinations to participants. In particular, household members provide blood samples from which cotinine concentration are later measured. One can in principle evaluate the degree of misreporting among subpopulations of interest. Unfortunately, the number of pregnant women in NHANES III is small: 296. Of these, 240 self-report not smoking, 96 of them having valid cotinine measures, one of whom has a cotinine concentration well above $(163 \mu \mathrm{g} / \mathrm{l})$ any standard cutoff for non-smokers. In the United Kingdom, the Health Survey of England (HSE) likewise collects serum and saliva samples and

\footnotetext{
${ }^{20}$ It should be noted that although external estimates of misclassification rates might be informative, Hausman, Abrevaya, and Scott-Morton [1998] point out that the Fisher information matrix associated to the maximization of (4) is not block diagonal. Consequently, inference based on the assumption of knowledge of the misclassification probabilities when they are estimated from external sources (as in Poterba and Summers [1995]) would be misleading since standard errors would likely be understated, as a result of the probabilities not being known with certainty.
} 
reports cotinine concentrations. However, the number of pregnant women in the HSE is around 1,100 , only 5 of which have valid cotinine measures.

\section{Data}

\subsection{Natality Detail}

To estimate the models outlined above, data are needed on birth outcomes, maternal smoking, demographic and socioeconomic characteristics of the mother, and the state in which the birth occurred. The data set I employ, the US Natality Detail, is a census of births in the United States between 1989 and 1996. The Natality data are taken directly from birth certificates and contain information regarding birth outcomes, demographic characteristics, and maternal smoking, as well as other information. Table 3 provides descriptive statistics for some of the variables included in the models below, broken down by race/ethnicity and self-reported smoking status.

The data on smoking status during pregnancy are drawn from mothers' answers to the following checkbox-format and an open-ended questions from the birth certificate:

\section{OTHER RISK FACTORS FOR THIS PREGNANCY}

(Complete all items)

Tobacco use during pregnancy. . . . . . . . . . Yes $\square$ No $\square$

Average number of cigarettes per day

Given the ambiguity of the question, it is unclear whether mothers perceive this as "any tobacco use at all during pregnancy," or "steady use throughout the pregnancy," or "tobacco use in the recent past," or some other possibility. Consequently, both smoking status and smoking intensity are likely to be subject to inaccuracies.

\subsection{Cigarette Taxes}

State and federal cigarette taxes are available on a monthly basis from the Tobacco Institute's Tax Burden on Tobacco, and are deflated by the CPI. Whereas Evans and Ringel [1999] match excise 
taxes to the Natality Detail based on month of conception, I remain agnostic about the timing of the decision to smoke or not during pregnancy and match the datasets based on birth month, as in Gruber and Köszegi [2001]. Elsewhere, since birth records also report state of residence separately from state of birth, there is a question as to which state is the relevant one. In practice, this decision has little impact on the analysis, as states of residence and of birth of the infant coincide 97.6\% of the time. I opt here for Evans and Ringel [1999]'s state definition, namely that in which the mother gave birth. ${ }^{21}$

Finally, there is an issue as to the validity of the exclusion restriction. As pointed out by Evans and Ringel [1999], a key assumption underlying the use of state cigarette taxes as an instrument for maternal smoking is that they have no independent effect on infant outcomes, other than through maternal smoking. Yet one might think that cigarettes taxes would be correlated with birth outcomes if a state earmarks a portion of cigarette tax revenues to tobacco control and/or to smoking cessation programs among pregnant women, in particular. However, according to the National Cancer Institute's State Cancer Legislative Database, ${ }^{22}$ which has logged all cancer-related state legislation (including cigarette taxes) since 1989, Massachusetts was the only state to fund tobacco control programs with the revenue from its cigarette taxes. In particular, Massachusetts' 1992 25-cent state cigarette tax increase funded the Massachusetts Tobacco Control Program, a comprehensive program that involved antismoking media campaigns, enforcement of local antismoking laws, and educational programs targeted primarily at teenagers and - importantly - pregnant women. ${ }^{23}$ In the empirical implementation, I have estimated models with and without Massachusetts, the results being insensitive to its inclusion. As a result, in spite of this

\footnotetext{
${ }^{21}$ Following Lien and Evans [2005], however, I discard observations from Worcester County, MA, whose smoking records are aberrant. See Lien and Evans [2005] for details.

${ }^{22}$ See http://www.scld-nci.net/.

${ }^{23}$ The one other exception is California. In 1989 and again in 1994, the legislature passed cigarette tax increases with references to maternal smoking, allocating a portion of the tax revenues to maternal smoking cessation programs. However, California is dropped from our sample since it has never recorded maternal smoking information on its birth certificates.
} 
confounder, I report results based on data that include Massachusetts. ${ }^{24}$

\section{Results}

Table 3 reports mean characteristics of African American, white, and Hispanic mothers, by selfreported smoking status. Across the three racial/ethnic groups, smokers tend to be of lower socioeconomic status. In particular, they tend to be less educated, are less likely to be married and, with the exception of African Americans, tend to be younger. Smokers also tend to have

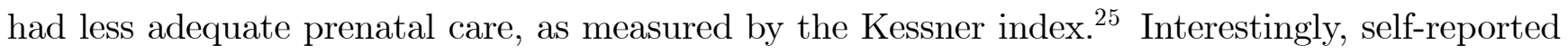
maternal smoking is also positively related to parity: smokers are more likely to be on their 3rd or higher birth.

Lastly, infant outcomes are markedly different for smokers. Birth weight, the outcome I focus on, is roughly 200 grams lower among infants of smokers than among those of non-smokers. Similarly, gestation lengths are on average shorter among self-reported smokers. African American smokers, for instance, are more than 5 percentage points more likely than non-smokers to have pregnancies of less than 36 weeks of gestation, whereas a gestation between 39 an 40 weeks is considered "healthy."

Formalizing these observations, Table 4 presents OLS estimates of the effect of (self-reported) maternal tobacco use on various outcomes. Somewhat surprising is the heterogeneity in these effects across race/ethnicity. Taking these estimates literally, infants of Hispanic smokers are 181 grams lighter than those of Hispanic nonsmokers, while the corresponding effect is nearer 235 grams for whites and blacks. However, given that black infants are on average 293 and 205 grams lighter than their white and Hispanic counterparts, respectively, the 238 gram downward shift in

\footnotetext{
${ }^{24}$ Lien [2001] finds no perceptible change in smoking behavior after the start of the media campaign.
}

\footnotetext{
${ }^{25}$ The Kessner index is a summary measure of the adequacy of a mother's prenatal care and is based on the number of prenatal care visits as a function of the gestation length of her pregnancy.
} 
the birth weight distribution of black infants induces a 9 percentage point increase in the likelihood of a low birth weight birth (i.e. birth weight $<2,500$ grams), or twice the effect for white and Hispanics.

Given the observable differences in characteristics across self-reported smokers and non-smokers, it is not unreasonable to expect unobservable determinants of infant birth weight to differ across the two groups as well. This motivates an instrumental variables approach, in which state cigarette excise taxes intrument for prenatal maternal smoking.

\subsection{Conventional IV}

Table 5 presents conventional IV estimates of the causal effect of prenatal maternal smoking on birth outcomes. The specifications largely follow Evans and Ringel [1999]. I employ a state fixed effects estimator, whereby smoking rates and birth weights within a state are examined before and after cigarette tax increases. Similarly, I control for month effects to account both for common macroeconomic shocks and for the pricing practices of US tobacco companies who, since mid-1983, have engaged in largely regular and coordinated price increases at the beginning and in the middle of each year. ${ }^{26}$

As mentioned earlier, in the absence of misreporting in maternal smoking, one might expect the OLS estimate to overstate the magnitude of the effect of smoking on birth outcomes if smoking is positively correlated with unobservable behavior that is harmful to infant health. As a result, assuming state cigarette taxes are legitimately excludable from the outcome equation, one would expect IV estimates to be smaller in magnitude than their OLS counterparts. The argument seems to hold for whites: the IV estimate is around 25 grams smaller in magnitude than its OLS analog. However, the estimates in Table 5 indicate substantial instability in the IV design. The birth weight cost of maternal smoking is an estimated 1, 184 grams for African Americans, which seems implausibly large given that the average African American infant weighs less than three times

\footnotetext{
${ }^{26}$ Howell, Congelio, and Yatsko [1994] provide an excellent and detailed history of the US tobacco industry's pricing practices.
} 
that amount $(3,130$ grams). This figure alone suggests some violation of the conventional IV assumptions and is consistent with an explanation rooted in misclassification of maternal tobacco use, which has the effect of inflating structural estimates.

In turn, smoking is estimated to increase birth weights by 771 grams among Hispanics (in a statistically significant manner). The unexpected direction of this effect is driven by the fact that, while the first stage estimate has the expected sign, the reduced form for Hispanics does not: higher state cigarette taxes are (weakly) associated with lower birth weights. Here again, however, the implausible magnitude of the estimated smoking-birth weight effect is consistent with misclassification error in the endogenous binary variable.

\subsection{GMM Approach}

As an illustration of the pitfalls of ignoring misclassification in the binary endogenous variable, Figures 2 and 3 report the results of a simulation in which the model is estimated according to the GMM procedure described above for a random subsample of the data, and imposing given values of the false negative rate, $\alpha_{1} \cdot{ }^{27}$ In particular, Figure 2 plots the first stage estimated average marginal effect of cigarette taxes on smoking participation as a function of $\alpha_{1}$ for the three racial/ethnic groups, and for different distributional assumptions on the first stage unobservable, $v$. It provides an illustration of the attenuating effect of misclassification on the first stage estimates of average marginal effects, with conventional probit and logit estimates (i.e. those corresponding to $\alpha_{1}=0$ in Figure 2) being considerably smaller in magnitude than those that allow for even moderate rates of false negative misclassification, particularly among whites. For instance, whereas a conventional logit predicts that a $\$ 1$ increase in cigarette taxes would reduce the likelihood of maternal smoking by just above 8 percentage points among whites, a 30\% false negative rate predicts that it would induce a decline of upwards of 12 percentage points. The analogous effects are much smaller in magnitude for African Americans and Hispanics, however.

\footnotetext{
${ }^{27}$ For the purposes of this simulation, I set the false positive rate, $\alpha_{0}$, to 0 since intuition suggests that it is likely to be close to zero. Unrestricted estimation of the model confirms this suspicion.
} 
Figure 3 plots the corresponding relationship between $\alpha_{1}$ and the second stage birth weight effects. Whereas their first stage effects are most sensitive to $\alpha_{1}$, the birth weight effects among whites are virtually unresponsive to the false negative rate up to $\alpha_{1}=30 \%$. Instead, the estimated birth weight effect among blacks is highly sensitive to misclassification, with estimated effects above 600 grams for a conventional logit first stage (i.e. imposing $\alpha_{1}=0$ ). That figure drops below 500 grams when $\alpha_{1}=30 \%$. Figure 3 also suggests that the estimated birth weight effect of prenatal maternal smoking can be sensitive to distributional assumptions. In particular, estimating a first stage probit that allows for misclassification, rather than a logit, adds on average 75 grams to the estimated birth weight effect for African Americans.

Table 6 reports the first estimates from the two-step GMM procedure. As suspected, the false positive rate is nearly zero for all three groups. The estimated false negative rates of $35 \%$ for blacks and $29 \%$ for whites, however, are substantial, while Hispanics misclassify at roughly half that rate. As mentioned earlier, Table 6 also reports $\min \left(\operatorname{Pr}\left(\widehat{S_{i}^{*}=} 1 \mid \mathbf{Z}_{i}\right)\right)=\min \left(F_{v}\left(\mathbf{Z}_{i}^{\prime} \hat{\mathbf{\Pi}}\right)\right)$ and $\max \left(\operatorname{Pr}\left(\widehat{S_{i}^{*}=1} \mid \mathbf{Z}_{i}\right)\right)=\max \left(F_{v}\left(\mathbf{Z}_{i}^{\prime} \hat{\mathbf{\Pi}}\right)\right)$ as rough measures of (semiparametric) identification of $\alpha_{0}$ and $\alpha_{1}$, respectively. Since a large proportion of pregnant women are estimated to be true nonsmokers, and are thus associated to very low probabilities of being actual smokers, $\alpha_{0}$ is very well identified, with $\min \left(F_{v}\left(\mathbf{Z}_{i}^{\prime} \hat{\mathbf{\Pi}}\right)\right)$ equaling $0.2 \%$ for blacks, $1.1 \%$ for whites, and $0.01 \%$ for Hispanics. The false negative rate, however, is less well identified, with $\max \left(F_{v}\left(\mathbf{Z}_{i}^{\prime} \hat{\mathbf{\Pi}}\right)\right)$ reaching 93\%, 96\%, and $75 \%$ for blacks, whites, and Hispanics, respectively, suggesting that the estimates of $\alpha_{1}$ rely more heavily on the parametric assumption.

Table 6 also reports the first stage average marginal effect of cigarette excise taxes on the probability of truly being a smoker, along with the implied elasticity, in the upper panel. These should be compared to the parameter estimates from linear first stages, with corresponding elasticities, reported in the lower panel. While the linear probability model implies roughly the same estimates of elasticities across the three racial/ethnic groups (around -0.55), the first stage logit that allows for misclassification suggests considerably more heterogeneity.

There are two reasons to expect differences in estimated elasticities relative to the linear probability model. First, the average marginal effects from logits with misclassification do not match 
the estimated coefficients on the tax variable in linear probability models, as should be expected in the context of a misclassified response variable. This argument relates to the term $\frac{\partial S}{\partial T a x}$ in the elasticity expression $\varepsilon_{D}=\left(\frac{\partial S}{\partial T a x} / \frac{\partial P}{\partial T a x}\right) \frac{\bar{P}}{S}$, seen in Section 2.3. In this particular setting, for instance, the linear first stage predicts that a dollar increase in cigarette excise taxes induces a 2.8 percentage point drop in smoking prevalence among pregnant Hispanic women. The logit with misclassification, however, predicts a much more muted 0.6 percentage point drop in prenatal maternal smoking.

The second reason relates to the term $\frac{\bar{P}}{\bar{S}}$ in the expression for the elasticity. The linear probability model takes the data at face value, and assumes that $\bar{S}^{*}=\bar{S}=\frac{1}{N} \sum_{i} S_{i}$, where $S_{i}$ is self-reported smoking status. When estimating models of misclassification, however, a better estimate of $\bar{S}^{*}$ is available, namely $\bar{S}^{*}=\frac{1}{N} \sum_{i} \operatorname{Pr}\left(\widehat{S_{i}^{*}=1} \mid \mathbf{Z}_{i}\right)=\frac{1}{N} \sum_{i} F_{v}\left(\mathbf{Z}_{i}^{\prime} \hat{\mathbf{\Pi}}\right)$. When $\alpha_{0} \approx 0$ and $\alpha_{1}>0, \frac{1}{N} \sum_{i} F_{v}\left(\mathbf{Z}_{i}^{\prime} \hat{\mathbf{\Pi}}\right)$ exceeds $\frac{1}{N} \sum_{i} S_{i}$, implying that $\frac{\bar{P}}{\bar{S}^{*}}<\frac{\bar{P}}{\bar{S}}$. For whites, the self reported smoking rate is 18.4 percent, while the true smoking prevalence implied by the model is estimated at 26.1 percent.

Finally, the parameter that is ultimately of interest is $\gamma$, the causal effect of prenatal maternal smoking on birth weight. For African Americans, the conventional IV estimate is -1, 184 grams, the surprising magnitude of which is suspected to be driven by misreporting in maternal smoking status. In turn, the GMM approach delivers a more "reasonable" estimate of -455 grams, which is consistent with the misclassification conjecture. However, it still exceeds the OLS (and misclassification-corrected OLS) estimates by almost 200 grams, as in some of Evans and Ringel [1999]'s initial estimates. Taking these figures literally suggests, counter-intuitively, that African Americans are positively selected into smoking since the smaller OLS estimate implies that unobservables correlated with maternal smoking status are pulling the birth weight effect towards zero, rather than away from it. Instead, the intuition that smoking status is correlated with unobservable behaviors that are harmful to infant health is restored for whites, with the corrected OLS estimate (-286 grams) exceeding the GMM estimate (-149 grams) in magnitude.

Since estimation and inference in the GMM framework proposed here rests critically on specification and functional form assumptions, the sensitivity of the results to included covariates is 
explored in Table 10 for African Americans and whites only. In these models, I add a quadratic in the number of prenatal care visits, and indicators for parity (i.e. birth order) and for the month prenatal care began. The estimated misclassification probabilities fall slightly, but the estimated maternal smoking birth weight effects equalizes somewhat across the races: the estimate falls (in magnitude) from 455 grams to 343 for African Americans, while it more than doubles for whites (from -149 to -321). However, as mentioned in Section 2.1, these particular additional controls have been found to be poorly reported in birth records and their inclusion may generate other biases in the estimation. Nonetheless, this does provide some evidence that, in this GMM framework, specification can have real consequences for parameter estimates.

In the subsequent sections, I estimate models separately by geographic region and by educational attainment, implicitly relaxing the assumption that misclassification rates are unrelated to observables, conditional on true smoking status.

\subsubsection{North vs. South}

The top panel of Table 7 details self-reported smoking prevalences among pregnant women by state and race/ethnicity. Figure 4 plots the self-reported smoking rate of African American women against that of whites. The relationship between the two is surprisingly weak. Furthermore, a peculiar geographical pattern emerges: whereas in several northern states (Connecticut, Illinois, Michigan, New Jersey, Pennsylvania, Wisconsin), the self-reported smoking rate among African Americans matches (and in some instances exceeds) that of whites, in southern states (Alabama, Florida, Georgia, Louisiana, Mississippi, South Carolina), it falls far short of the white self-reported smoking rate. For instance, in Pennsylvania, 23\% of African American and 19\% of white pregnant women report tobacco use during pregnancy. In Alabama, however, the corresponding figures are $7 \%$ for blacks and $18 \%$ for whites. In this section, I examine whether these geographical differences in tobacco use can be explained by misreporting, or whether they are real.

Table 8A reports GMM and conventional IV estimates for blacks and whites, separated by geographical regions defined above. The linear IV estimate of $\gamma$ for southern blacks is $-1,338$ grams, a magnitude that seems implausibly large given that an infant born to a southern African 
American woman weighs on average 3, 132 grams. The exaggerated birth weight effect of maternal smoking estimated by conventional IV might instead be symptomatic of severe misreporting among this group of women. As confirmation, when the analogous model is estimated by GMM, the birth weight effect drops to a more reasonable 206 grams, driven, it seems, by a substantial estimated false negative rate of $61 \%$. The misclassification rate among northern African American women, in turn, exactly matches the aggregate false negative rate for blacks reported in Table 6. It is unclear, however, why misreporting would be so much more severe among African American women in the South than elsewhere. Perhaps the stigma associated to prenatal maternal smoking is more intense for this group, or incomplete birth certificates are simply filled by administrators as non-smokers. This remains an open question.

The high misclassification rate among southern blacks implies that while only $8 \%$ of mothers in this group self-report tobacco use during pregnancy, the estimated unconditional probability of truly being a smoker is $20 \%$, which falls much closer to the smoking rates in other regions. Notice that while the average marginal effect of cigarette taxes on smoking participation estimated by GMM (-0.36) exceeds in magnitude that of the conventional IV model $(-0.18)$, the elasticity implied by the former is smaller in magnitude than that implied by the latter. This is a product of the fact that the average smoking rate purged of misclassification, $\bar{S}^{*}=\frac{1}{N} \sum_{i} F_{v}\left(\mathbf{Z}_{i}^{\prime} \hat{\mathbf{\Pi}}\right)=0.199$, is much larger than the estimate of smoking prevalence based on self-reports, $\bar{S}=\frac{1}{N} \sum_{i} S_{i}=0.081$, such that the denominator of $\varepsilon_{D}=\left(\frac{\partial S}{\partial T a x} / \frac{\partial P}{\partial T a x}\right) \frac{\bar{P}}{\bar{S}}$ is much larger.

The estimates in Table 8A are also informative regarding selection into smoking. Whereas in the pooled sample, blacks appear positively selected into smoking, ${ }^{28}$ southern African Americans instead appear to be negatively selected, as do whites across the two regions. Northern blacks seem to be driving the positive selection at the aggregate level: the GMM estimate of $\gamma$ for northern blacks ( -487 grams) closely matches the pooled estimate.

Finally, in an effort to assess the degree of sensitivity to parametric assumptions, I re-estimate the North-South GMM models using a probit with misclassification rather than a logit. The results

\footnotetext{
${ }^{28}$ Since the magnitude of the GMM estimate exceeds that of the misclassification-corrected OLS estimate.
} 
are reported in Table 8B. The estimate of $\alpha_{1}$ for African American southerners (58.7\%) remains close to its logit analog, as do the average marginal effects of taxes and implied elasticities. The estimated birth weight effect of smoking, however, is slightly larger in magnitude than in the logit (-222 vs. -206 grams). These remarks roughly generalize to northern blacks, and to northern and southern whites (See Tables $8 \mathrm{~A}$ and 8B).

\subsubsection{Educational Attainment}

The lower panel of Table 7 provides self-reported smoking rates by race and educational attainment. Given that these measures of smoking participation decline precipitously with education, I estimate OLS, conventional IV, and GMM models of the effect of prenatal maternal smoking on infant birth weight for whites and blacks separately, by three categories of educational attainment: less than 12 years, exactly 12 years, and more than 12 years of education. The results are reported in Table 9 .

The GMM estimated birth weight effect is remarkably stable across educational categories for African Americans, ranging from -396 to -359 grams. Misreporting for these women has a slight gradient in education, with more highly educated African American mothers having slightly higher misclassification rates (39\% for those with more than 12 years of education versus $29 \%$ for those with less than 12 years of education). However, the misclassification problem has its most pronounced effect on conventional IV estimates for African American women with less than 12 years of education. For this group, conventional IV produces an estimated birth weight cost of

maternal smoking close to 2 kilograms (1,980 grams)! Correcting for misclassification yields a more reasonable estimate of -396 grams.

For whites, the gradient in misclassification with respect to education is much more pronounced. At levels of education less than or equal to 12 years, the estimated false positive rates almost match the false negative rates. At the highest level of education, however, misclassification among white mothers takes the form exclusively of false negatives, with $\hat{\alpha}_{1}=35 \%$. Whereas it is stable across education groups for blacks, the estimated birth weight effect of prenatal maternal smoking for whites is moderate $(\approx 220$ grams) for mothers with high and low levels of education, but large for 
mothers with 12 years of education (close to 500 grams).

Interestingly, while only suggestive, the education gradient in misclassification is consistent with the hypothesis that more educated mothers are more aware of the deleterious effects of maternal smoking and are consequently subject to more stigma associated with prenatal tobacco use. If so, they may also be more prone to misrepresenting their smoking status on the birth certificate. Though this evidence is far from definitive, it is consistent with the theory that education improves allocative efficiency, in the form of better understanding of the infant health production function (as posited by Rosenzweig and Schultz [1982]), coupled with social stigma regarding prenatal smoking (which need not be increasing in education per se).

\subsection{Interpretation of Results}

It should be noted that interpretation of the birth weight effects estimated in this paper is not as straightforward as has been suggested. As reviewed by Lumley, Oliver, Chamberlain, and Oakley [2004], prenatal maternal smoking is also thought to have a separate causal effect on gestation length. In particular, gestations among smokers tend to be shorter than among non-smokers. Yet gestation is another key input into birth weight, with longer gestations being related to higher birth weights. As a result, the estimates produced here, which do not control for gestation, should be considered gross of gestation effects and should therefore not be taken as evidence that prenatal maternal smoking causes intrauterine growth retardation.

Elsewhere, there is a sense in which identification of $\gamma$ is less straightforward than has been assumed. In particular, suppose a pregnant woman quits smoking in the face of higher state cigarette excise taxes, but substitutes into other behaviors that have independent effects on birth

weight as a result of quitting. Then the estimate of $\gamma$ will capture the gross effect of this change in behavior, rather than the effect of smoking cessation only. For instance, it is well known than tobacco use acts as an appetite suppressant. If a mother quits smoking during pregnancy, but develops a stronger appetite as a result, then the estimates of $\gamma$ reported here will not distinguish between these potentially distinct effects. If heavier food consumption is related to heavier infants, for instance, then my estimates would overstate the impact of smoking on birth weight since they 
are comparing mothers who were induced to heavier eating as a result of tax-induced smoking cessation, to mothers who still smoke, and whose appetites were held constant.

\section{Conclusion}

This paper exploits recent parametric methods to reexamine the relationship between prenatal maternal smoking and an early marker of infant health in the presence of misclassified maternal tobacco use. Conventional IV methods are ill-suited for this problem since misclassification errors are necessarily (negatively) correlated with true smoking status, and by extension with first stage instruments. The resulting attenuation in first stage coefficient estimates carries over to structural parameter estimates, artificially inflating them.

These observations provide an explanation for the surprising result that conventional IV estimates of the effect of maternal smoking on birth weight match and often exceed their OLS counterparts in magnitude. This is puzzling because, ex ante, one would expect smoking to be correlated with unobservable maternal behaviors that might be harmful to infant health, such as alcohol use, poor nutrition, etc. If maternal smoking is misreported, however, the omitted variables bias that (arguably) pulls the OLS estimator away from zero may be offset by the misreporting bias that pulls it towards zero. The net impact on the OLS estimator is ambiguous, implying that it provides a poor benchmarks for alternative other estimators.

When misclassification of maternal smoking is ignored, conventional instrumental variables methods can deliver perverse estimates of the effect of prenatal maternal tobacco use on birth weight. The linear IV estimate among African American women with less than 12 years of education, for example, is $-1,980$ grams, or two thirds of the average birth weight of infants born to mothers in this group. When misreporting in maternal smoking is taken into account, the estimate drops to -396 grams, which is remarkably close to the 400 gram benchmark established by Permut and Hebel [1989].

Finally, the problem of misclassified endogenous treatments isn't limited to prenatal maternal smoking and its effects on infant health. The methods developed here have applications in a variety of other settings in which measurement error has either been documented in binary indicators or 
is suspected. For instance, misclassification problems have been identified in self-reported health insurance coverage (Card, Hildreth, and Shore-Sheppard [2004]), union status (Jakubson [1986], Card [1996]), food stamp participation (Bollinger and David [1997]), and educational attainment (Kane, Rouse, and Staiger [1999]), among numerous others (Bound, Brown, and Mathiowetz [2001]). Furthermore, when the outcome of interest is itself categorical, the methods in this paper can be adapted to modify conventional binary probit analysis, for instance.

\section{References}

Abrevaya, J. (2006): "Estimating the Effect of Smoking on Birth Outcomes Using a Matched Panel Data Approach," Journal of Applied Econometrics, 21(4), 489-519.

Adda, J., And F. Cornaglia (2006): "Taxes, Cigarette Consumption and Smoking Intensity," American Economic Review, 96(4), 1013-1028.

Aigner, D. J. (1973): "Regression with a Binary Independent Variable Subject to Errors of Observation," Journal of Econometrics, 1(1), 49-59.

Almond, D., K. Y. Chay, and D. S. Lee (2005): "The Costs of Low Birth Weight," Quarterly Journal of Economics, 120(3).

Ananth, C., D. Savitz, And E. Luther (1996): "Maternal Cigarette Smoking as a Risk Factor for Placental Abruption, Placenta Previa, and Uterine Bleeding in Pregnancy," American Journal of Epidemiology, 144, 881-9.

Anderson, H., J. Bland, And J. Peacock (1992): "The Effect of Smoking on Fetal Growth," in Effects of Smoking on the Fetus, Neonate, and Child, ed. by P. D., and A. E., pp. 89-105. Oxford University Press Inc, New York, NY.

Atkinson, A. B., J. Gomulka, And N. Stern (1984): Household Expenditure on Tobacco 19701980: Evidence from the Family Expenditure Survey. London School of Economics, London. 
Bardy, A. H., T. Seppälä, P. Lillgunde, J. M. Kataja, P. Koskela, J. Pikkarainen, and V. K. Hillesmaa (1993): "Objectively Measured Tobacco Exposure During Pregnancy: Neonatal Effects and Relation to Maternal Smoking," British Journal of Obstetrics and Gynaecology, 100(8), 721-6.

Becker, G. S., M. Grossman, and K. M. Murphy (1994): "An Empirical Analysis of Cigarette Addiction," American Economic Review, 84(3), 396-418.

Black, D. A., M. C. Berger, and F. A. Scott (2000): "Bounding Parameter Estimates with Nonclassical Measurement Error," Journal of the American Statistical Association, 95(451), $739-48$.

Bollinger, C. R. (1996): "Bounding Mean Regressions When a Binary Regressor is Mismeasured," Journal of Econometrics, 73(2), 387-99.

Bollinger, C. R., and M. H. David (1997): "Modeling Discrete Choice With Response Error: Food Stamp Participation," Journal of the American Statistical Association, 92(439), 827-835.

Bound, J., C. C. Brown, and N. Mathiowetz (2001): "Measurement Error in Survey Data," in Handbook of Econometrics, ed. by E. Learner, and J. Heckman, vol. 5, pp. 3705-3843. North Holland Publishing, New York.

Boyd, N., R. Windsor, L. Perkins, and J. Lowe (1998): "Quality of Measurement of Smoking Status by Self-Report and Saliva Cotinine Among Pregnant Women," Maternal and Child Health Journal, 2(2), 77-83.

Bradford, W. D. (2003): "Pregnancy and the Demand for Cigarettes," American Economic Review, 93(5), 1752-63.

Britton, G., J. Brinthaupt, J. Stehleand, and G. James (2004): "Comparison of SelfReported Smoking and Urinary Cotinine Levels in a Rural Pregnant Population," Journal of Obstetric, Gynecologic, and Neonatal Nursing, 33(3), 306-11. 
Buescher, P., K. Taylor, M. Davis, and J. M. Bowling (1993): "The Quality of the New Birth Certificate Data: A Validation Study in North Carolina," American Journal of Public Health, 83(8), 1163-5.

CARD, D. (1996): "The Effect of Unions on the Structure of Wages: A Longitudinal Analysis," Econometrica, 64(4), 957-79.

Card, D., A. K. Hildreth, and L. D. Shore-Sheppard (2004): "The Measurement of Medicaid Coverage in the SIPP: Evidence From a Comparison of Matched Records," Journal of Business and Economic Statistics, 22(4), 410-420.

Chaloupka, F. J., And K. E. Warner (2000): "The Economics of Smoking," in Handbook of Health Economics, ed. by A. Culyer, and J. Newhouse, vol. 1, Part 2, chap. 29, pp. 1539-1627. Elsevier, North Holland.

Chaloupka, F. J., and H. Wechsler (1997): "Price, Tobacco Control Policies and Smoking Among Young Adults," Journal of Health Economics, 16(3), 359-373.

Colman, G., M. Grossman, and T. Joyce (2003): "The Effect of Cigarette Excise Taxes on Smoking Before, During and After Pregnancy," Journal of Health Economics, 22(6), 1053-72.

CraGG, J. G. (1971): "Some Statistical Models for Limited Dependent Variables with Application to the Demand for Durable Goods," Econometrica, 39(5), 829-45.

Cutler, D. M., J. Gruber, R. S. Hartman, M. Landrum, J. Newhouse, and M. B. Rosenthal (2002): "The Economic Impacts of the Tobacco Settlement," Journal of Policy Analysis and Management, 21(1), 1-19.

Elster, J. (1979): Ulysses and the Sirens: Studies in Rationality and Irrationality. Cambridge University Press, Cambridge.

England, L. J., J. S. Kendrick, P. M. Gargiullo, S. C. Zahniser, and W. H. Hannon (2001): "Measures of Maternal Tobacco Exposure and Infant Birth Weight at Term," American Journal of Epidemiology, 153(10), 954-60. 
Evans, W. N., and M. C. Farrelly (1998): "The Compensating Behavior of Smokers: Taxes, Tar, and Nicotine," RAND Journal of Economics, 29(3), 578-95.

Evans, W. N., And J. S. Ringel (1999): "Can Higher Cigarettes Taxes Improve Birth Outcomes?," Journal of Public Economics, 72, 135-54.

Evans, W. N., J. S. Ringel, and D. Stech (1999): "Tobacco Taxes and Public Policy to Discourage Smoking," Tax Policy and the Economy, 13, 1-55.

Farrelly, M., And J. Bray (1998): "Response to Increases in Cigarette Prices by Race/Ethnicity, Income, and Age GroupsŮUnited States, 1976-1993," Journal of the American Medical Association, 280(23), 1979-80.

Floyd, R., S. Zahniser, E. Gunter, and J. Kendrick (1991): "Smoking During Pregnancy: Prevalence, Effects and Intervention Strategies," Birth, 18, 47-53.

Frazis, H., And M. A. Loewenstein (2003): "Estimating Linear Regressions with Mismeasured, Possibly Endogenous, Binary Explanatory Variables," Journal of Econometrics, 117(1), 151-178.

Freeman, R. B. (1984): "Longitudinal Analyses of the Effects of Trade Unions," Journal of Labor Economics, 2(1), 1-26.

Gruber, J., And B. Köszegi (2001): "Is Addiction Rational? Theory and Evidence," Quarterly Journal of Economics, 116(4), 1261-1303.

Gruber, J., And J. Zinman (2001): "Youth Smoking in the United States: Evidence and Implications," in Risky Behavior Among Youth: An Economic Analysis, ed. by J. Gruber, pp. 69-120. The University of Chicago Press, Chicago.

Harris, J. E. (1987): "The 1983 Increase in the Federal Cigarette Excise Tax," Tax Policy and the Economy, 1.

Hausman, J., J. Abrevaya, and F. Scott-Morton (1998): "Misclassification of the Dependent Variable in a Discrete-Response Setting," Journal of Econometrics, 87, 239-69. 
Howell, C., F. Congelio, and R. Yatsko (1994): "Pricing Practices for Tobacco Products, 1980-94," Monthly Labor Review, 117(12), 3-16.

Jakubson, G. (1986): "Measurement Error in Binary Explanatory Variables in Panel Data Models: Why Do Cross Section and Panel Estimates of the Union Wage Effect Differ?," Princeton University Industrial Relations Section Working Paper No. 209.

Jones, A. M. (1989): “A Double-Hurdle Model of Cigarette Consumption," Journal of Applied Econometrics, 4, 23-39.

KAI, L., AND D. J. Poirier (2001): "An Econometric Analysis of the Birth Process by Racial/Ethnic Groups," in Bayesian Methods with Applications to Science, Policy, and Official Statistics, Selected Papers from ISBA 2000: The Sixth World Meeting of the International Society for Bayesian Analysis, ed. by E. I. George, pp. 321-30.

Kane, T. J., C. E. Rouse, and D. Staiger (1999): "Estimating Returns to Schooling When Schooling is Misreported," NBER Working Paper 7235.

Keeler, T., T.-W. Hu, P. Barnett, and W. Manning (1993): "Taxation, Regulation and Addiction: A Demand Function for Cigarettes Based on Time-Series Evidence," Journal of Health Economics, 12(1), 1-18.

Klebanoff, M., R. Levine, J. Clemens, R. DerSimonian, and D. Wilkins (1998): "Serum Cotinine Concentration and Self-Reported Smoking During Pregnancy," American Journal of Epidemiology, 148(3), 259-62.

Lambers, D., And K. Clark (1996): "The Maternal and Fetal Physiologic Effects of Nicotine," Seminars in Perinatology, 20, 115-26.

Lewit, E., And D. Coate (1982): "The Potential for Using Excise Taxes to Reduce Smoking," Journal of Health Economics, 1(2), 121-45.

LiEn, D. (2001): "Measuring the Inputs to Infant Health: Evidence from Natural Experiments," Ph.D. thesis, University of Maryland, College Park. 
Lien, D. S., and W. N. Evans (2005): "Estimating the Impact of Large Cigarette Tax Hikes: The Case of Maternal Smoking and Infant Birth Weight," Journal of Human Resources, 40(2), $373-92$.

Lumley, J., S. Oliver, C. Chamberlain, and L. OAkley (2004): "Interventions for Promoting Smoking Cessation During Pregnancy," The Cochrane Database of Systematic Reviews, 4(Art. No.: CD001055.pub2. DOI: 10.1002/14651858.CD001055.pub2).

Ness, R., J. Grisso, and N. Hirschinger (1999): "Cocaine and Tobacco Use and the Risk of Spontaneous Abortion," New England Journal of Medicine, 340, 333-9.

Neuhaus, J. M. (1999): "Bias and Efficiency Loss Due to Misclassified Responses in Binary Regression," Biometrika, 86(4), 843-855.

Newey, W. K. (1984): "A Method of Moments Interpretation of Sequential Estimators," Economics Letters, 14, 201-206.

Newey, W. K., and D. McFadden (1994): "Large Sample Estimation and Hypothesis Testing," in Handbook of Econometrics, ed. by R. F. Engle, and D. L. McFadden, chap. 36, pp. 2111-2245. Elsevier, North Holland.

Permut, T., and J. Hebel (1989): "Simultaneous Equation Estimation in a Clinical Trial of the Effect of Smoking on Birth Weight," Biometrics, 45, 619-22.

PiCCinini, K. (2005): "State Fiscal Policy: Channels and Consequences," Working Paper.

Piper, J., E. J. Mitchel, M. Snowden, C. Hall, M. Adams, and P. Taylor (1993): "Validation of 1989 Tennessee Birth Certificates Using Maternal and Newborn Hospital Records," American Journal of Epidemiology, 137(7), 758-68.

Poterba, J. M., And L. H. Summers (1995): "Unemployment Benefits and Labor Market Transitions: A Multinomial Logit Model with Errors in Classification," The Review of Economics and Statistics, LXXVII(2), 207-16. 
Reichman, N. E., and E. M. Hade (2001): "Validation of Birth Certificate Data: A Study of Women in New Jersey's HealthStart Program," Annals of Epidemiology, 11(3), 186-93.

Ringel, J. S., And W. N. Evans (2001): "Cigarette Taxes and Smoking During Pregnancy," American Journal of Public Health, 91(11), 1851-6.

Roohan, P., R. Josberger, J. Acar, P. Dabir, H. Feder, and P. Gagliano (2003): "Validation of Birth Certificate Data in New York State," Journal of Community Health, 28(5), $335-46$.

Rosenzweig, M., And T. P. Schultz (1982): "The Behavior of Mothers as Inputs to Child Health: The Determinants of Birth Weight, Gestation, and Rate of Fetal Growth," in Economics Aspects of Health, ed. by V. R. Fuchs, Chicago, IL. University of Chicago Press.

Rosenzweig, M. R., And T. P. Schultz (1983): "Estimating a Household Production Function: Heterogeneity, the Demand for Health Outputs, and Their Effects on Birth Weight," Journal of Political Economy, 91(5), 723-46.

Sexton, M., And J. Hebel (1984): "A Clinical Trial of Change in Maternal Smoking and its Effects on Birth Weight," Journal of the American Medical Association, 251, 911-15.

Surgeon General (2001): Women and Smoking: A Report of the Surgeon GeneralDepartment of Health and Human Services, Centers for Disease Control and Prevention, National Center for Chronic Disease Prevention and Health Promotion, Office on Smoking and Health, Washington, DC.

Tobacco Institute (1998): The Tax Burden on Tobacco: Historical Compilation, vol. 30. Tobacco Institute, Washington, DC.

Torelli, P. A. (2000): "Maternal Smoking and Birth Outcomes: A Nonparametric Approach," Mimeo.

WebB, D., N. Boyd, D. Messina, And R. Windsor (2003): "The Discrepancy Between SelfReported Smoking Status and Urine Continine Levels Among Women Enrolled in Prenatal Care 
at Four Publicly Funded Clinical Sites," Journal of Public Health Management and Practice, $9(4), 322-5$.

Winston, G. (1980): "Addiction and Backsliding: A Theory of Compulsive Consumption," Journal of Economic Behavior and Organization, 1(4), 295-324.

Zollinger, T., M. Przybylski, and R. Gamache (2005): "Reliability of Indiana Birth Certificate Data Compared to Medical Records," Annals of Epidemiology, 16(1), 1-10.

\section{A Appendix}

\section{A.1 Bias of the OLS estimator of the coefficient on the misclassified regressor}

In a model with a mismeasured dichotomous regressor and other perfectly measured explanatory variables, Card [1996] and Frazis and Loewenstein [2003] provide expressions for the magnitude of the bias in OLS due to misclassification. In particular, if $S_{i}^{*}$ is mismeasured but uncorrelated with unobservables (so that the OLS regression of $Y_{i}$ on $S_{i}^{*}$ and other observables would deliver a consistent estimate of $\gamma$ ), then OLS of $Y_{i}$ on the error-ridden version of $S_{i}^{*}, S_{i}$, produces the following inconsistency in $\hat{\gamma}_{O L S}$ :

$$
\gamma=p \lim \hat{\gamma}_{O L S} \times \frac{p(1-p)\left(1-\alpha_{0}-\alpha_{1}\right)(1-R)}{\left(p-\alpha_{0}\right)\left(1-p-\alpha_{1}\right)-R p(1-p)}
$$

where $p \equiv \mathbb{E}(S)=\alpha_{0}+\left(1-\alpha_{0}-\alpha_{1}\right) \mathbb{E}\left(S^{*}\right)$ and $R$ is the theoretical $R^{2}$ from a regression of $S$ on $X$ :

$$
R \equiv \frac{\operatorname{Cov}(X, S)[\operatorname{Var}(X)]^{-1} \operatorname{Cov}(X, S)^{\prime}}{p(1-p)}
$$




\section{A.2 Cochrane Reviews}

Table 1: Lumley, Oliver, Chamberlain, and Oakley [2004] summary of randomized and quasirandomized trials of smoking cessation programs implemented during pregnancy. Birth weights are in grams.

\begin{tabular}{|c|c|c|c|c|c|c|c|c|c|c|}
\hline \multirow[b]{2}{*}{ Study } & \multicolumn{3}{|c|}{ Treatment } & 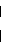 & \multicolumn{3}{|c|}{ Control } & \multicolumn{3}{|l|}{ ' } \\
\hline & $\mathrm{N}$ & Mean & SD & & $\mathrm{N}$ & Mean & SD & 1 & $\mathrm{~T}-\mathrm{C}$ & $95 \%$ CI \\
\hline Donovan [1977] & 263 & 3,172 & 500 & I & 289 & 3,184 & 500 & ' & -12 & {$[-95.5,71.5]$} \\
\hline Ershoff [1989] & 118 & 3,366 & 500 & ' & 109 & 3,309 & 500 & 1 & 57 & {$[-73.2,187.2]$} \\
\hline Haddow [1991] & 1,423 & 3,263 & 542 & i & 1,425 & 3,229 & 537 & 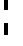 & 34 & {$[-5.6,73.6]$} \\
\hline Hegaard [2003] & 327 & 3,401 & 500 & $\begin{array}{l}1 \\
\vdots\end{array}$ & 320 & 3,433 & 500 & : & -32 & {$[-109.1,45.1]$} \\
\hline Hjalmarson [1991] & 492 & 3,430 & 500 & ' & 231 & 3,359 & 500 & ' & 71 & {$[-7.2,149.2]$} \\
\hline MacArthur [1987] & 493 & 3,164 & 500 & 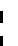 & 489 & 3,130 & 500 & 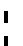 & 34 & {$[-28.6,96.6]$} \\
\hline Malchodi [2003] & 67 & 3,100 & 481 & i & 75 & 3,072 & 614 & 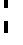 & 28 & {$[-152.5,208.5]$} \\
\hline Panjari [1999] & 337 & 3,250 & 526 & I & 391 & 3,166 & 589 & ' & 84 & {$[3 ., 165]$.} \\
\hline RADIUS [1995] & 1,768 & 3,352 & 528 & 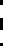 & 1,803 & 3,349 & 544 & : & 3 & {$[-32.2,38.2]$} \\
\hline Rush [1992] & 175 & 3,163 & 606 & $\begin{array}{l}1 \\
1\end{array}$ & 144 & 3,119 & 443 & ! & 44 & {$[-71.3,159.3]$} \\
\hline Secker-Walker [1994] & 279 & 3,291 & 468 & 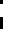 & 282 & 3,255 & 466 & 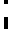 & 36 & {$[-41.3,113.3]$} \\
\hline Secker-Walker [1998] & 135 & 3,256 & 452 & $\begin{array}{l}1 \\
1\end{array}$ & 141 & 3,221 & 506 & ' & 35 & {$[-78.1,148.1]$} \\
\hline Sexton [1984] & 463 & 3,278 & 627 & i & 472 & 3,186 & 566 & ! & 92 & {$[15.4,168.6]$} \\
\hline Tappin [2000] & 48 & 3,205 & 500 & ' & 49 & 3,271 & 500 & ' & -66 & {$[-265 ., 133]$.} \\
\hline Thornton [1997] & 380 & 3,267 & 624 & 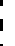 & 380 & 3,266 & 613 & ' & 1 & {$[-87 ., 89]$.} \\
\hline Wisborg [2000] & 124 & 3,457 & 500 & 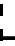 & 126 & 3,271 & 500 & 1 & 186 & {$[62 ., 310]$.} \\
\hline Total & 6,892 & & & I & 6,726 & & & 1 & 33.03 & {$[11.3,54.7]$} \\
\hline
\end{tabular}


Table 2. Replication Of First Stage of Evans \& Ringel (1999) with Tax Interacted with Race/Ethnicity Data Organized by Conception Month, 1989-1992

\begin{tabular}{|c|c|c|c|c|c|c|c|c|c|}
\hline \multirow[b]{2}{*}{ Indep Var } & \multicolumn{3}{|c|}{ Dep. Var. $=$ Smoker } & \multicolumn{3}{|c|}{ Dep. Var. = Cigarettes $/$ Day } & \multicolumn{3}{|c|}{ Dep. Var. = Cigs $/$ Day Among Smokers } \\
\hline & Model (1) & Model (2) & Model (3) & Model (1) & Model (2) & Model (3) & Model (1) & Model (2) & Model (3) \\
\hline $\operatorname{Tax}$ & $\begin{array}{l}-0.0372 \\
(0.0053)\end{array}$ & $\begin{array}{l}-0.0241 \\
(0.0052)\end{array}$ & $\begin{array}{l}-0.0244 \\
(0.0052)\end{array}$ & $\begin{array}{l}-0.2238 \\
(0.0822)\end{array}$ & $\begin{array}{c}0.0028 \\
(0.0804)\end{array}$ & $\begin{array}{l}-0.0047 \\
(0.0803)\end{array}$ & $\begin{array}{c}0.0498 \\
(0.2951)\end{array}$ & $\begin{array}{l}-0.3257 \\
(0.2948)\end{array}$ & $\begin{array}{l}-0.3204 \\
(0.2942)\end{array}$ \\
\hline
\end{tabular}

\begin{tabular}{|c|c|c|c|c|c|c|c|c|c|}
\hline \multirow[b]{2}{*}{ Inped Var } & \multicolumn{3}{|c|}{ Dep. Var. $=$ Smoker } & \multicolumn{3}{|c|}{ Dep. Var. = Cigarettes/Day } & \multicolumn{3}{|c|}{ Dep. Var. = Cigs/Day Among Smokers } \\
\hline & Model (1) & Model (2) & Model (3) & Model (1) & Model (2) & Model (3) & Model (1) & Model (2) & Model (3) \\
\hline $\operatorname{Tax}$ & $\begin{array}{l}-0.0874 \\
(0.0056)\end{array}$ & $\begin{array}{l}-0.0556 \\
(0.0054)\end{array}$ & $\begin{array}{l}-0.0563 \\
(0.0054)\end{array}$ & $\begin{array}{l}-1.2371 \\
(0.0861)\end{array}$ & $\begin{array}{l}-0.6932 \\
(0.0843)\end{array}$ & $\begin{array}{l}-0.7061 \\
(0.0842)\end{array}$ & $\begin{array}{l}-0.9500 \\
(0.2998)\end{array}$ & $\begin{array}{l}-0.9372 \\
(0.2994)\end{array}$ & $\begin{array}{l}-0.9419 \\
(0.2988)\end{array}$ \\
\hline Tax*Black & $\begin{array}{c}0.1552 \\
(0.0041)\end{array}$ & $\begin{array}{c}0.1210 \\
(0.0040)\end{array}$ & $\begin{array}{c}0.1213 \\
(0.0040)\end{array}$ & $\begin{array}{c}2.8119 \\
(0.0637)\end{array}$ & $\begin{array}{c}2.2735 \\
(0.0622)\end{array}$ & $\begin{array}{c}2.2906 \\
(0.0621)\end{array}$ & $\begin{array}{c}5.3357 \\
(0.2262)\end{array}$ & $\begin{array}{c}3.9576 \\
(0.2259)\end{array}$ & $\begin{array}{c}4.0011 \\
(0.2254)\end{array}$ \\
\hline Tax*Hispanic & $\begin{array}{c}0.0862 \\
(0.0059)\end{array}$ & $\begin{array}{c}0.0226 \\
(0.0058)\end{array}$ & $\begin{array}{c}0.0242 \\
(0.0058)\end{array}$ & $\begin{array}{c}2.0798 \\
(0.0907)\end{array}$ & $\begin{array}{c}1.0026 \\
(0.0895)\end{array}$ & $\begin{array}{c}1.0175 \\
(0.0894)\end{array}$ & $\begin{array}{c}1.7474 \\
(0.4704)\end{array}$ & $\begin{array}{l}-0.1613 \\
(0.4818)\end{array}$ & $\begin{array}{l}-0.1176 \\
(0.4808)\end{array}$ \\
\hline Tax*Other & $\begin{array}{c}0.1877 \\
(0.0094)\end{array}$ & $\begin{array}{c}0.2530 \\
(0.0094)\end{array}$ & $\begin{array}{c}0.2518 \\
(0.0093)\end{array}$ & $\begin{array}{c}2.7502 \\
(0.1444)\end{array}$ & $\begin{array}{c}3.6081 \\
(0.1450)\end{array}$ & $\begin{array}{c}3.5824 \\
(0.1449)\end{array}$ & $\begin{array}{c}2.0949 \\
(0.6515)\end{array}$ & $\begin{array}{c}0.8993 \\
(0.6670)\end{array}$ & $\begin{array}{c}0.9020 \\
(0.6656)\end{array}$ \\
\hline
\end{tabular}

Notes: Model (1) controls for age and race of the mother, an indicator for the sex of the child, state and time effects, and real cigarette taxes. Model (2) adds a dummy for whether the mother is married, indicators for years of education, parity of birth fixed-effects, and indicators for the Kessner index of adequacy of prenatal care. Model (3) tries to control for the health habits of mothers and adds a set of indicators for maternal weight gain. Standard errors are clustered by state*month and are shown in brackets below point estimates. $\mathrm{N}=10,271,597$. 
Table 3. Mean Characteristics of Mothers by Race/Ethnicity and Self-Reported Smoking Status Natality Detail, 1989-1996

\begin{tabular}{|c|c|c|c|c|c|c|}
\hline \multirow[b]{2}{*}{$\underline{\text { Variable }}$} & \multicolumn{2}{|c|}{ African American } & \multicolumn{2}{|c|}{ White } & \multicolumn{2}{|c|}{ Hispanic } \\
\hline & Non-Smokers & Smokers & Non-Smokers & Smokers & Non-Smokers & Smokers \\
\hline Birth Weight & 3,161 & 2,916 & 3,473 & 3,203 & 3,346 & 3,159 \\
\hline Low Birth Weight = $1(\mathrm{BW}<2500$ grams $)$ & 0.104 & 0.202 & 0.038 & 0.087 & 0.051 & 0.101 \\
\hline Very Low Birth Weight $=\mathbf{1}(\mathrm{BW}<1500$ grams $)$ & 0.023 & 0.034 & 0.006 & 0.011 & 0.008 & 0.014 \\
\hline Smoker & 0.00 & 1.00 & 0.00 & 1.00 & 0.00 & 1.00 \\
\hline Cigarettes per day & 0.00 & 9.69 & 0.00 & 13.11 & 0.00 & 9.89 \\
\hline Real State+Federal Cigarette Tax (1982-84 dollars) & 0.32 & 0.32 & 0.34 & 0.33 & 0.39 & 0.37 \\
\hline Boy & 0.507 & 0.507 & 0.513 & 0.513 & 0.510 & 0.511 \\
\hline Married & 0.330 & 0.199 & 0.860 & 0.618 & 0.682 & 0.439 \\
\hline Age & 24.1 & 26.5 & 27.5 & 25.5 & 25.3 & 25.0 \\
\hline Fraction Aged $<24$ & 0.535 & 0.337 & 0.257 & 0.419 & 0.427 & 0.457 \\
\hline Fraction Aged $>35$ & 0.045 & 0.068 & 0.082 & 0.050 & 0.055 & 0.048 \\
\hline Kessner Index: Prenatal Care $=$ Adequate & 0.564 & 0.407 & 0.804 & 0.665 & 0.554 & 0.505 \\
\hline Kessner Index: Prenatal Care $=$ Intermediate & 0.284 & 0.312 & 0.148 & 0.240 & 0.279 & 0.296 \\
\hline Kessner Index: Prenatal Care $=$ Inadequate & 0.112 & 0.234 & 0.028 & 0.072 & 0.123 & 0.153 \\
\hline Kessner Index: Prenatal Care $=$ Unknown & 0.040 & 0.047 & 0.020 & 0.022 & 0.044 & 0.046 \\
\hline Live Birth Order: First Child & 0.410 & 0.183 & 0.440 & 0.375 & 0.400 & 0.294 \\
\hline Live Birth Order: Second Child & 0.301 & 0.271 & 0.340 & 0.338 & 0.303 & 0.293 \\
\hline Live Birth Order: Third Child or Higher & 0.289 & 0.546 & 0.220 & 0.287 & 0.297 & 0.412 \\
\hline Gestation: 36 weeks and below & 0.165 & 0.229 & 0.073 & 0.102 & 0.099 & 0.124 \\
\hline Gestation: 37 - 39 weeks & 0.439 & 0.420 & 0.431 & 0.415 & 0.444 & 0.421 \\
\hline Gestation: 40 weeks & 0.195 & 0.163 & 0.248 & 0.220 & 0.231 & 0.211 \\
\hline Gestation: 41 weeks & 0.107 & 0.090 & 0.149 & 0.138 & 0.128 & 0.126 \\
\hline Gestation: 42 weeks and over & 0.094 & 0.098 & 0.099 & 0.125 & 0.098 & 0.119 \\
\hline Mother's Education $=0-8$ years & 0.027 & 0.029 & 0.015 & 0.043 & 0.211 & 0.125 \\
\hline Mother's Education $=9-11$ years & 0.253 & 0.385 & 0.087 & 0.291 & 0.258 & 0.393 \\
\hline Mother's Education $=12$ years & 0.421 & 0.416 & 0.351 & 0.462 & 0.308 & 0.347 \\
\hline Mother's Education $=13-15$ years & 0.211 & 0.145 & 0.254 & 0.159 & 0.138 & 0.107 \\
\hline Mother's Education $=16$ years and over & 0.089 & 0.026 & 0.293 & 0.046 & 0.085 & 0.027 \\
\hline Number of Observations & $3,208,248$ & 466,091 & $11,853,789$ & $2,683,607$ & $2,384,246$ & 152,380 \\
\hline
\end{tabular}

Note: The Kessner Index is a summary measure of the adequacy of a mother's prenatal care and is based on length of gestation, number of prenatal visits, and date of initial prenatal visit. 
Table 4. OLS Estimated Effects of Self-Reported Smoking Participation on Outcomes Natality Detail, 1989-1996

\begin{tabular}{|c|c|c|c|}
\hline Outcome & Black & White & Hispanic \\
\hline Birth Weight & $\begin{array}{c}-238 \\
(1.07)\end{array}$ & $\begin{array}{c}-235 \\
(0.40)\end{array}$ & $\begin{array}{l}-181 \\
(1.57)\end{array}$ \\
\hline Low Birth Weight $=\mathbf{1}(\mathrm{BW}<2500)$ & $\begin{array}{c}0.0883 \\
(0.0006)\end{array}$ & $\begin{array}{c}0.0400 \\
(0.0002)\end{array}$ & $\begin{array}{c}0.0456 \\
(0.0008)\end{array}$ \\
\hline Gestation (in weeks) & $\begin{array}{l}-0.4012 \\
(0.0077)\end{array}$ & $\begin{array}{l}-0.1199 \\
(0.0054)\end{array}$ & $\begin{array}{l}-0.1272 \\
(0.0082)\end{array}$ \\
\hline Assisted ventilation, $>30$ minutes & $\begin{array}{c}0.0038 \\
(0.0002)\end{array}$ & $\begin{array}{c}0.0015 \\
(0.0002)\end{array}$ & $\begin{array}{c}0.0023 \\
(0.0003)\end{array}$ \\
\hline Number of Observations & $3,545,624$ & $14,299,029$ & $2,442,919$ \\
\hline
\end{tabular}

Notes: These models control for infant's sex, mother's marital status, mother's cohort, indicators for mother's education, indicators for her age, and state and month fixed effects. The Apgar score rates an infant's appearance, pulse, responsiveness, muscle activity, and breathing on a scale of zero to 2 ( 2 being the strongest rating). The numbers are then totaled with 10 being a perfect score. Standard errors are robust to heteroskedasticity. 
Table 5. Conventional IV Estimates of the Effect of Self-Reported Prenatal Smoking on Outcomes

First Stage Effect of State Taxes on Smoking Participation

\begin{tabular}{lccc}
\hline \hline Dependent Variable & Black & White & Hispanic \\
\hline Smoke (= 1 if self-reported smoker) & -0.056 & -0.087 & -0.028 \\
& $(0.005)$ & $(0.006)$ & $(0.005)$ \\
Number of Obs & $3,545,624$ & $14,299,029$ & $2,442,919$ \\
\hline
\end{tabular}

Second Stage Effect of Prenatal Maternal Smoking on Infant Outcomes

\begin{tabular}{lccc}
\hline \hline Outcome & Black & White & Hispanic \\
\hline Birthweight (grams) & $-1,184$ & -209 & 771 \\
& $(171)$ & $(43)$ & $(322)$ \\
Gestation (weeks) & -2.66 & -1.98 & -4.08 \\
& $(0.880)$ & $(0.340)$ & $(2.095)$ \\
Five Minute Apgar & -1.602 & -0.148 & -0.691 \\
& $(0.280)$ & $(0.073)$ & $(0.425)$ \\
Assisted ventilation, $<30$ minutes & & & 0.372 \\
Assisted ventilation, $>30$ minutes & 0.240 & -0.033 & $(0.124)$ \\
& $(0.072)$ & $(0.025)$ & 0.183 \\
\end{tabular}

Notes: In the first stage, the state plus federal cigarette excise taxes that were effective during the month of birth are used as an instrument for maternal smoking. Taxes are expressed in constant 1982-84 dollars. These models control for infant's sex, mother's marital status, mother's cohort, indicators for mother's education, indicators for her age, and state and month fixed effects. Standard errors are clustered by state*month. 
Table 6. GMM Estimates of Effect of Prenatal Maternal Smoking on Birth Weight by Race/Ethnicity First Stage Logit Allowing for Misclassification

\begin{tabular}{|c|c|c|c|c|c|c|}
\hline & \multicolumn{2}{|c|}{ Black } & \multicolumn{2}{|c|}{ White } & \multicolumn{2}{|c|}{ Hispanic } \\
\hline$\alpha_{0}$ & 0.000 & NA & 0.000 & NA & 0.005 & $(0.0002)$ \\
\hline$\alpha_{1}$ & 0.350 & $(0.0051)$ & 0.293 & $(0.0062)$ & 0.166 & (0.0198) \\
\hline $\begin{array}{l}\text { Avg. Marg. Effect of Cig. Tax } \\
\text { On Smoking Participation }\end{array}$ & -0.045 & $(0.0078)$ & -0.118 & $(0.0105)$ & -0.006 & $(0.0025)$ \\
\hline Implied Elasticity & -0.268 & & -0.533 & & -0.109 & \\
\hline Implied $\operatorname{Pr}[$ Smoke $]$ & 0.194 & & 0.261 & & 0.066 & \\
\hline $\operatorname{Min}(\operatorname{Pr}[$ Smoke |Z] $)$ & 0.002 & & 0.011 & & 0.0001 & \\
\hline $\operatorname{Max}(\operatorname{Pr}[$ Smoke $\mid \mathrm{Z}])$ & 0.934 & & 0.961 & & 0.748 & \\
\hline \multicolumn{7}{|l|}{$\underline{\text { Second Stage }}$} \\
\hline$\gamma$ & -455 & (119) & -149 & (39) & -268 & (181) \\
\hline \multicolumn{7}{|l|}{$\underline{\text { Reference }}$} \\
\hline Average Birth Weight & 3,133 & & 3,426 & & 3,338 & \\
\hline Self-Reported Smoking Rate & 0.126 & & 0.184 & & 0.064 & \\
\hline OLS & -238 & $(1.07)$ & -235 & $(0.40)$ & -181 & $(1.57)$ \\
\hline Corrected OLS & -283 & & -286 & & -202 & \\
\hline Conventional IV & $-1,184$ & $(171)$ & -209 & $(43)$ & 771 & $(322)$ \\
\hline First Stage Linear Effect of Tax & -0.056 & $(0.005)$ & -0.087 & $(0.006)$ & -0.028 & $(0.005)$ \\
\hline Implied Elasticity & -0.516 & & -0.556 & & -0.548 & \\
\hline
\end{tabular}

Notes: These models control for infant's sex, mother's marital status, mother's cohort, indicators for mother's education, indicators for her age, and state and month fixed effects. Standard errors for the first stage GMM estimates are not clustered by state*month, though all others are. The first stage is a logit that allows for misclassification, as described by Hausman et al [1998], and expresses the conditional probability of being a self-reported smoker as a function of conditional misclassification rates and the probability of truly being a smoker. In addition to the above regressors, the first stage controls for the state plus federal cigarette excise taxes that were effective during the month of birth. Taxes are expressed in constant 1982-84 dollars. In the upper panel, the minimum and the maximum fitted probabilities of truly being a smoker are reported. As detailed in the text, these provide a rough measure of identification of the false positive, $\alpha_{0}$, and false negative, $\alpha_{1}$, rates, respectively. NAs are reported for the standard error of $\alpha_{0}$ when it is estimated to be zero. This occurs as a result of constraining $\alpha_{0}$ to be non-negative. 
Table 7. Self Reported Smoking by State and Level of Education

\begin{tabular}{|c|c|c|c|c|c|c|}
\hline \multirow[b]{2}{*}{ State } & \multicolumn{2}{|c|}{ Black } & \multicolumn{2}{|c|}{ White } & \multicolumn{2}{|c|}{ Hispanic } \\
\hline & Smoker $=1$ & $\mathrm{~N}$ & Smoker $=1$ & $\mathrm{~N}$ & Smoker $=1$ & $\mathrm{~N}$ \\
\hline Alabama & $7.39 \%$ & 150,872 & $18.28 \%$ & 290,149 & $6.86 \%$ & 4,123 \\
\hline Alaska & $11.55 \%$ & 3,620 & $17.39 \%$ & 52,276 & $9.19 \%$ & 3,590 \\
\hline Arizona & $16.00 \%$ & 16,775 & $17.86 \%$ & 278,982 & $5.37 \%$ & 169,043 \\
\hline Arkansas & $10.22 \%$ & 52,267 & $23.64 \%$ & 189,776 & $7.79 \%$ & 4,853 \\
\hline Colorado & $16.88 \%$ & 19,047 & $15.83 \%$ & 287,312 & $12.14 \%$ & 75,269 \\
\hline Connecticut & $10.78 \%$ & 25,381 & $10.15 \%$ & 179,799 & $8.83 \%$ & 36,601 \\
\hline Delaware & $14.65 \%$ & 18,037 & $16.84 \%$ & 60,587 & $5.76 \%$ & 3,596 \\
\hline District of Columbia & $11.45 \%$ & 81,868 & $4.85 \%$ & 42,071 & $0.70 \%$ & 9,173 \\
\hline Florida & $8.18 \%$ & 317,241 & $21.17 \%$ & 857,096 & $4.00 \%$ & 229,975 \\
\hline Georgia & $7.26 \%$ & 287,554 & $16.38 \%$ & 492,590 & $2.96 \%$ & 28,464 \\
\hline Hawaii & $4.06 \%$ & 1,108 & $8.33 \%$ & 8,935 & $10.58 \%$ & 4,340 \\
\hline Idaho & $10.05 \%$ & 378 & $15.22 \%$ & 106,139 & $5.54 \%$ & 12,016 \\
\hline Illinois & $16.78 \%$ & 291,087 & $17.99 \%$ & 835,787 & $3.57 \%$ & 213,845 \\
\hline Iowa & $22.22 \%$ & 7,543 & $19.49 \%$ & 258,780 & $10.20 \%$ & 8,009 \\
\hline Kansas & $10.54 \%$ & 22,521 & $13.71 \%$ & 220,084 & $5.18 \%$ & 18,905 \\
\hline Kentucky & $18.43 \%$ & 32,701 & $26.11 \%$ & 329,071 & $14.00 \%$ & 2,778 \\
\hline Louisiana & $8.42 \%$ & 188,435 & $15.68 \%$ & 258,857 & $4.75 \%$ & 7,650 \\
\hline Maine & $14.76 \%$ & 542 & $19.72 \%$ & 106,968 & $19.77 \%$ & 2,478 \\
\hline Maryland & $12.13 \%$ & 107,441 & $14.26 \%$ & 260,372 & $4.03 \%$ & 17,762 \\
\hline Massachusetts & $16.80 \%$ & 50,467 & $22.14 \%$ & 509,688 & $12.20 \%$ & 62,514 \\
\hline Michigan & $18.23 \%$ & 200,579 & $20.18 \%$ & 721,921 & $21.23 \%$ & 73,504 \\
\hline Minnesota & $19.68 \%$ & 14,938 & $12.21 \%$ & 360,116 & $10.50 \%$ & 38,129 \\
\hline Mississippi & $7.71 \%$ & 148,620 & $20.92 \%$ & 155,324 & $6.28 \%$ & 1,418 \\
\hline Missouri & $17.86 \%$ & 91,886 & $23.02 \%$ & 467,821 & $10.81 \%$ & 8,893 \\
\hline Montana & $17.84 \%$ & 241 & $16.72 \%$ & 68,768 & $21.72 \%$ & 4,706 \\
\hline Nebraska & $19.36 \%$ & 8,532 & $19.10 \%$ & 136,509 & $12.78 \%$ & 10,535 \\
\hline Nevada & $16.08 \%$ & 14,374 & $21.95 \%$ & 109,063 & $4.56 \%$ & 33,067 \\
\hline New Hampshire & $20.21 \%$ & 287 & $17.54 \%$ & 49,068 & $20.46 \%$ & 64,154 \\
\hline New Jersey & $14.37 \%$ & 140,480 & $10.92 \%$ & 488,382 & $5.62 \%$ & 123,651 \\
\hline New Mexico & $14.76 \%$ & 3,415 & $16.04 \%$ & 72,293 & $8.94 \%$ & 88,038 \\
\hline North Carolina & $13.72 \%$ & 214,067 & $20.18 \%$ & 509,434 & $3.61 \%$ & 21,601 \\
\hline North Dakota & $9.01 \%$ & 566 & $16.79 \%$ & 63,818 & $14.22 \%$ & 2,545 \\
\hline Ohio & $20.45 \%$ & 176,783 & $22.61 \%$ & 972,817 & $14.44 \%$ & 21,383 \\
\hline Oklahoma & $10.29 \%$ & 20,376 & $17.22 \%$ & 147,252 & $6.93 \%$ & 9,551 \\
\hline Oregon & $25.15 \%$ & 6,697 & $20.98 \%$ & 273,646 & $5.05 \%$ & 29,444 \\
\hline Pennsylvania & $22.92 \%$ & 162,247 & $18.72 \%$ & 951,313 & $13.90 \%$ & 44,633 \\
\hline Rhode Island & $19.84 \%$ & 6,551 & $20.67 \%$ & 76,784 & $15.08 \%$ & 18,876 \\
\hline South Carolina & $9.97 \%$ & 146,342 & $21.97 \%$ & 227,227 & $6.63 \%$ & 4,946 \\
\hline Tennessee & $11.28 \%$ & 131,781 & $22.24 \%$ & 434,999 & $7.06 \%$ & 6,206 \\
\hline Texas & $7.08 \%$ & 278,669 & $13.78 \%$ & 987,894 & $2.54 \%$ & 908,001 \\
\hline Utah & $19.62 \%$ & 1,534 & $9.87 \%$ & 253,896 & $8.89 \%$ & 19,651 \\
\hline Vermont & $17.75 \%$ & 169 & $19.23 \%$ & 49,525 & $18.84 \%$ & 1,486 \\
\hline Virginia & $12.00 \%$ & 162,990 & $16.12 \%$ & 465,494 & $2.67 \%$ & 30,045 \\
\hline Washington & $15.53 \%$ & 10,849 & $18.35 \%$ & 247,006 & $6.06 \%$ & 35,704 \\
\hline West Virginia & $16.54 \%$ & 5,411 & $20.87 \%$ & 149,051 & $5.68 \%$ & 651 \\
\hline Wisconsin & $26.78 \%$ & 50,650 & $20.89 \%$ & 432,386 & $12.93 \%$ & 17,241 \\
\hline Wyoming & $18.81 \%$ & 420 & $22.73 \%$ & 40,270 & $14.79 \%$ & 3,583 \\
\hline All States & $12.69 \%$ & $3,674,339$ & $18.46 \%$ & $14,537,396$ & $6.01 \%$ & $2,536,626$ \\
\hline
\end{tabular}

\begin{tabular}{ccr} 
& \multicolumn{2}{c}{ Black } \\
Mother's Education & Smoker $=1$ & \multicolumn{1}{c}{$\mathrm{N}$} \\
\hline Educ $=0-8$ years & $13.35 \%$ & 100,455 \\
Educ $=9-11$ years & $18.13 \%$ & 989,786 \\
Educ $=12$ years & $12.54 \%$ & $1,544,481$ \\
Educ $=13-15$ years & $9.10 \%$ & 743,571 \\
Educ $=16$ years and over & $4.04 \%$ & 296,046
\end{tabular}

\begin{tabular}{cr}
\multicolumn{2}{c}{ White } \\
Smoker $=1$ & \multicolumn{1}{c}{$\mathrm{N}$} \\
\hline $39.39 \%$ & 291,185 \\
$42.99 \%$ & $1,813,798$ \\
$22.95 \%$ & $5,399,099$ \\
$12.41 \%$ & $3,436,340$ \\
$3.43 \%$ & $3,596,974$
\end{tabular}

\begin{tabular}{cc}
\multicolumn{2}{c}{ Hispanic } \\
Smoker $=1$ & $\mathrm{~N}$ \\
\hline $3.66 \%$ & 521,768 \\
$8.89 \%$ & 674,522 \\
$6.71 \%$ & 786,825 \\
$4.72 \%$ & 345,923 \\
$2.01 \%$ & 207,588
\end{tabular}

$$
\begin{aligned}
& =\text { South } \\
& =\text { North }
\end{aligned}
$$


Table 8A. GMM Estimates of Effect of Prenatal Maternal Smoking on Birth Weight by Region

First Stage Logit Allowing for Misclassification

\begin{tabular}{|c|c|c|c|c|c|c|c|c|}
\hline \multirow{2}{*}{ First Stage } & \multicolumn{2}{|c|}{ Southern Blacks } & \multicolumn{2}{|c|}{ Northern Blacks } & \multicolumn{2}{|c|}{ Southern Whites } & \multicolumn{2}{|c|}{ Northern Whites } \\
\hline & & & & & & & & \\
\hline$\alpha_{0}$ & 0.004 & $(0.0004)$ & 0.006 & $(0.0014)$ & 0.000 & NA & 0.002 & $(0.0007)$ \\
\hline$\alpha_{1}$ & 0.613 & $(0.0042)$ & 0.336 & $(0.0082)$ & 0.350 & $(0.0040)$ & 0.257 & $(0.0049)$ \\
\hline $\begin{array}{l}\text { Avg. Marg. Effect of Cig. Tax } \\
\text { On Smoking Participation }\end{array}$ & -0.362 & $(0.0480)$ & -0.051 & $(0.0111)$ & -0.189 & $(0.0364)$ & -0.078 & $(0.0046)$ \\
\hline Implied Elasticity & -1.773 & & -0.206 & & -0.635 & & -0.358 & \\
\hline Implied $\operatorname{Pr}[$ Smoke] & 0.199 & & 0.268 & & 0.295 & & 0.236 & \\
\hline $\operatorname{Min}(\operatorname{Pr}[$ Smoke |Z] $)$ & 0.001 & & 0.003 & & 0.0172 & & 0.014 & \\
\hline $\operatorname{Max}(\operatorname{Pr}[$ Smoke $\mid \mathrm{Z}])$ & 0.958 & & 0.940 & & 0.967 & & 0.910 & \\
\hline \multicolumn{9}{|l|}{$\underline{\text { Second Stage }}$} \\
\hline$\gamma$ & -206 & (74) & -487 & (138) & -116 & $(49)$ & -226 & (83) \\
\hline \multicolumn{9}{|l|}{ Reference } \\
\hline Average Birth Weight & 3,132 & & 3,116 & & 3,407 & & 3,445 & \\
\hline Self-Reported Smoking Rate & 0.081 & & 0.183 & & 0.192 & & 0.176 & \\
\hline OLS & -242 & $(2.09)$ & -242 & $(1.84)$ & -240 & $(0.99)$ & -232 & $(0.81)$ \\
\hline Corrected OLS & -360 & & -313 & & -312 & & -274 & \\
\hline Conventional IV & $-1,338$ & (338) & -663 & $(247)$ & -708 & $(210)$ & -8 & $(69)$ \\
\hline First Stage Linear Effect of Tax & -0.182 & $(0.031)$ & -0.044 & $(0.008)$ & -0.169 & $(0.033)$ & -0.066 & $(0.006)$ \\
\hline Implied Elasticity & -2.206 & & -0.261 & & -0.870 & & -0.407 & \\
\hline Number of Observations & $1,239,064$ & & 870,424 & & $2,281,243$ & & $3,609,588$ & \\
\hline
\end{tabular}

Notes: These models control for infant's sex, mother's marital status, mother's cohort, indicators for mother's education, indicators for her age, and state and month fixed effects. Standard errors for the first stage GMM estimates are not clustered by state*month, though all others are. The first stage is a logit that allows for misclassification, as described by Hausman et al [1998], and expresses the conditional probability of being a self-reported smoker as a function of conditional misclassification rates and the probability of truly being a smoker. In addition to the above regressors, the first stage controls for the state plus federal cigarette excise taxes that were effective during the month of birth. Taxes are expressed in constant 1982-84 dollars. In the upper panel, the minimum and the maximum fitted probabilities of truly being a smoker are reported. As detailed in the text, these provide a rough measure of identification of the false positive, $\alpha_{0}$, and false negative, $\alpha_{1}$, rates, respectively. NAs are reported for the standard error of $\alpha_{0}$ when it is estimated to be zero. This occurs as a result of constraining $\alpha_{0}$ to be non-negative. The South is comprised of Alabama, Florida, Georgia, Louisiana, Mississippi, and South Carolina, while the North is comprised of Connecticut, Illinois, Michigan, New Jersey, Pennsylvania, Wisconsin. 
Table 8B. GMM Estimates of Effect of Prenatal Maternal Smoking on Birth Weight by Region First Stage Probit Allowing for Misclassification

\begin{tabular}{|c|c|c|c|c|c|c|c|c|}
\hline \multirow{2}{*}{ First Stage } & \multicolumn{2}{|c|}{ Southern Blacks } & \multicolumn{2}{|c|}{ Northern Blacks } & \multicolumn{2}{|c|}{ Southern Whites } & \multicolumn{2}{|c|}{ Northern Whites } \\
\hline & & & & & & & & \\
\hline$\alpha_{0}$ & 0.009 & $(0.0003)$ & 0.018 & $(0.0012)$ & 0.000 & NA & 0.012 & $(0.0006)$ \\
\hline$\alpha_{1}$ & 0.587 & $(0.0057)$ & 0.330 & $(0.0095)$ & 0.329 & $(0.0052)$ & 0.258 & $(0.0056)$ \\
\hline $\begin{array}{l}\text { Avg. Marg. Effect of Cig. Tax } \\
\text { On Smoking Participation }\end{array}$ & -0.343 & $(0.0455)$ & -0.051 & $(0.0112)$ & -0.185 & $(0.0356)$ & -0.079 & $(0.0047)$ \\
\hline Implied Elasticity & -1.882 & & -0.218 & & -0.639 & & -0.378 & \\
\hline Implied $\operatorname{Pr}[$ Smoke] & 0.178 & & 0.253 & & 0.287 & & 0.225 & \\
\hline $\operatorname{Min}(\operatorname{Pr}[$ Smoke $\mid \mathrm{Z}])$ & 0.000 & & 0.000 & & 0.0111 & & 0.005 & \\
\hline $\operatorname{Max}(\operatorname{Pr}[$ Smoke |Z] $)$ & 0.956 & & 0.951 & & 0.970 & & 0.922 & \\
\hline \multicolumn{9}{|l|}{$\underline{\text { Second Stage }}$} \\
\hline$\gamma$ & -222 & (69) & -489 & $(134)$ & -132 & (54) & -224 & $(78)$ \\
\hline \multicolumn{9}{|l|}{ Reference } \\
\hline Average Birth Weight & 3,132 & & 3,116 & & 3,407 & & 3,445 & \\
\hline Self-Reported Smoking Rate & 0.081 & & 0.183 & & 0.192 & & 0.176 & \\
\hline OLS & -242 & $(2.09)$ & -242 & $(1.84)$ & -240 & $(0.99)$ & -232 & $(0.81)$ \\
\hline Corrected OLS & -369 & & -332 & & -304 & & -292 & \\
\hline Conventional IV & $-1,338$ & (338) & -663 & $(247)$ & -708 & $(210)$ & -8 & $(69)$ \\
\hline First Stage Linear Effect of Tax & -0.182 & $(0.031)$ & -0.044 & $(0.008)$ & -0.169 & $(0.033)$ & -0.066 & $(0.006)$ \\
\hline Implied Elasticity & -2.206 & & -0.261 & & -0.870 & & -0.407 & \\
\hline Number of Observations & $1,239,064$ & & 870,424 & & $2,281,243$ & & $3,609,588$ & \\
\hline
\end{tabular}

Notes: These models control for infant's sex, mother's marital status, mother's cohort, indicators for mother's education, indicators for her age, and state and month fixed effects. Standard errors for the first stage GMM estimates are not clustered by state*month, though all others are. The first stage is a probit that allows for misclassification, as described by Hausman et al [1998], and expresses the conditional probability of being a self-reported smoker as a function of conditional misclassification rates and the probability of truly being a smoker. In addition to the above regressors, the first stage controls for the state plus federal cigarette excise taxes that were effective during the month of birth. Taxes are expressed in constant 1982-84 dollars. In the upper panel, the minimum and the maximum fitted probabilities of truly being a smoker are reported. As detailed in the text, these provide a rough measure of identification of the false positive, $\alpha_{0}$, and false negative, $\alpha_{1}$, rates, respectively. NAs are reported for the standard error of $\alpha_{0}$ when it is estimated to be zero. This occurs as a result of constraining $\alpha_{0}$ to be non-negative. The South is comprised of Alabama, Florida, Georgia, Louisiana, Mississippi, and South Carolina, while the North is comprised of Connecticut, Illinois, Michigan, New Jersey, Pennsylvania, Wisconsin. 
Table 9. GMM Estimates of Effect of Prenatal Maternal Smoking on Birth Weight by Educational Attainment First Stage Logit Allowing for Misclassification

\begin{tabular}{|c|c|c|c|c|c|c|c|c|c|c|c|c|}
\hline \multirow[b]{2}{*}{ First Stage } & \multicolumn{2}{|c|}{ Blacks with Educ $<12$} & \multicolumn{2}{|c|}{ Blacks with Educ $=12$} & \multicolumn{2}{|c|}{ Blacks with Educ $>12$} & \multicolumn{2}{|c|}{ Whites with Educ $<12$} & \multicolumn{2}{|c|}{ Whites with Educ $=12$} & \multicolumn{2}{|c|}{ Whites with Educ $>12$} \\
\hline & & & & & & & & & & & & \\
\hline$\alpha_{0}$ & 0.000 & NA & 0.000 & NA & 0.001 & $(0.0004)$ & 0.207 & $(0.0031)$ & 0.078 & $(0.0022)$ & 0.000 & NA \\
\hline$\alpha_{1}$ & 0.294 & $(0.0066)$ & 0.385 & $(0.0076)$ & 0.387 & $(0.0156)$ & 0.157 & $(0.0123)$ & 0.098 & $(0.0248)$ & 0.353 & $(0.0073)$ \\
\hline $\begin{array}{l}\text { Avg. Marg. Effect of Cig. Tax } \\
\text { On Smoking Participation }\end{array}$ & -0.022 & $(0.0108)$ & -0.028 & $(0.0047)$ & -0.026 & $(0.0038)$ & -0.048 & $(0.0084)$ & -0.050 & $(0.0032)$ & -0.056 & $(0.0015)$ \\
\hline Implied Elasticity & -0.102 & & -0.158 & & -0.249 & & -0.163 & & -0.317 & & -0.554 & \\
\hline Implied $\operatorname{Pr}[$ Smoke $]$ & 0.251 & & 0.203 & & 0.123 & & 0.343 & & 0.184 & & 0.121 & \\
\hline $\operatorname{Min}(\operatorname{Pr}[$ Smoke $\mid \mathrm{Z}])$ & 0.007 & & 0.006 & & 0.0015 & & 0.000 & & 0.010 & & 0.006 & \\
\hline $\operatorname{Max}(\operatorname{Pr}[$ Smoke $\mid \mathrm{Z}])$ & 0.938 & & 0.907 & & 0.834 & & 0.864 & & 0.768 & & 0.832 & \\
\hline \multicolumn{13}{|l|}{ Second Stage } \\
\hline$\gamma$ & -396 & (113) & -383 & $(107)$ & -359 & (146) & -221 & (91) & -492 & (134) & -223 & (83) \\
\hline \multicolumn{13}{|l|}{$\underline{\text { Reference }}$} \\
\hline Average Birth Weight & 3,060 & & 3,134 & & 3,205 & & 3,284 & & 3,407 & & 3,482 & \\
\hline Self-Reported Smoking Rate & 0.176 & & 0.125 & & 0.076 & & 0.425 & & 0.229 & & 0.078 & \\
\hline OLS & -222 & $(1.67)$ & -247 & $(1.59)$ & -260 & $(2.41)$ & -235 & $(0.81)$ & -241 & $(0.58)$ & -225 & $(0.77)$ \\
\hline Corrected OLS & -271 & & -295 & & -294 & & -441 & & -357 & & -245 & \\
\hline Conventional IV & $-1,980$ & $(681)$ & -861 & $(172)$ & -642 & $(220)$ & -513 & (121) & -365 & $(71)$ & -27 & $(52)$ \\
\hline First Stage Linear Effect of Tax & -0.024 & $(0.010)$ & -0.074 & $(0.006)$ & -0.064 & $(0.006)$ & -0.078 & $(0.010)$ & -0.094 & $(0.007)$ & -0.083 & $(0.008)$ \\
\hline Implied Elasticity & -0.155 & & -0.689 & & -0.982 & & -0.212 & & -0.482 & & -1.271 & \\
\hline Number of Observations & $1,047,769$ & & $1,488,953$ & & $1,008,902$ & & $2,058,640$ & & $5,308,007$ & & $6,932,382$ & \\
\hline
\end{tabular}

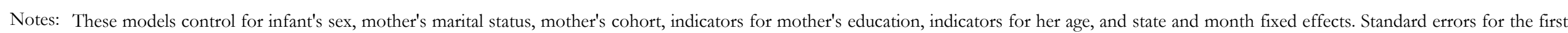

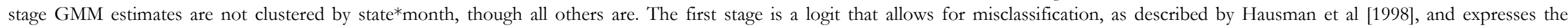

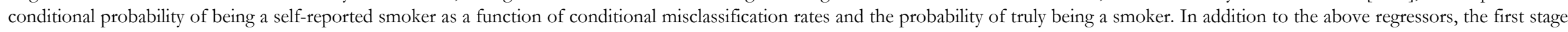

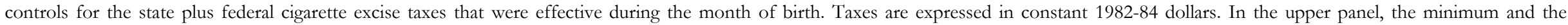

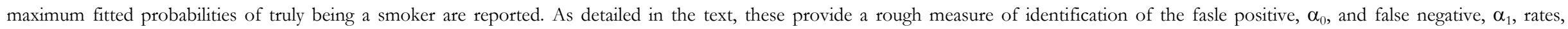
respectively. NAs are reported for the standard error of $\alpha_{0}$ when it is estimated to be zero. This occurs as a result of constraining $\alpha_{0}$ to be non-negative. 
Table 10. GMM Estimates of Effect of Prenatal Maternal Smoking on Birth Weight by Race/Ethnicity First Stage Logit Allowing for Misclassification

\begin{tabular}{|c|c|c|c|c|}
\hline & \multicolumn{2}{|c|}{ Black } & \multicolumn{2}{|c|}{ White } \\
\hline \multicolumn{5}{|l|}{ First Stage } \\
\hline$\alpha_{0}$ & 0.000 & NA & 0.000 & NA \\
\hline$\alpha_{1}$ & 0.271 & $(0.0054)$ & 0.274 & $(0.0060)$ \\
\hline $\begin{array}{l}\text { Avg. Marg. Effect of Cig. Tax } \\
\text { On Smoking Participation }\end{array}$ & -0.053 & $(0.0068)$ & -0.118 & $(0.0102)$ \\
\hline Implied Elasticity & -0.352 & & -0.551 & \\
\hline Implied $\operatorname{Pr}[$ Smoke $]$ & 0.173 & & 0.253 & \\
\hline $\operatorname{Min}(\operatorname{Pr}[$ Smoke |Z] $)$ & 0.002 & & 0.004 & \\
\hline $\operatorname{Max}(\operatorname{Pr}[$ Smoke $\mid \mathrm{Z}])$ & 0.966 & & 0.967 & \\
\hline \multicolumn{5}{|l|}{$\underline{\text { Second Stage }}$} \\
\hline$\gamma$ & -343 & (97) & -321 & $(82)$ \\
\hline \multicolumn{5}{|l|}{$\underline{\text { Reference }}$} \\
\hline Average Birth Weight & 3,133 & & 3,425 & \\
\hline Self-Reported Smoking Rate & 0.126 & & 0.185 & \\
\hline OLS & -205 & $(1.43)$ & -235 & $(0.87)$ \\
\hline Corrected OLS & -232 & & -282 & \\
\hline Conventional IV & -952 & $(160)$ & -87 & $(88)$ \\
\hline First Stage Linear Effect of Tax & -0.078 & $(0.007)$ & -0.085 & $(0.008)$ \\
\hline Implied Elasticity & -0.717 & & -0.544 & \\
\hline
\end{tabular}

Notes: These models control for infant's sex, mother's marital status, mother's cohort, indicators for mother's education, indicators for her age, and state and month fixed effects, as well as a quadratic in the number of prenatal visits, dummies for the month prenatal care began, and live birth order. Standard errors for the first stage GMM estimates are not clustered by state*month, though all others are. The first stage is a logit that allows for misclassification, as described by Hausman et al [1998], and expresses the conditional probability of being a self-reported smoker as a function of conditional misclassification rates and the probability of truly being a smoker. In addition to the above regressors, the first stage controls for the state plus federal cigarette excise taxes that were effective during the month of birth. Taxes are expressed in constant 1982-84 dollars. In the upper panel, the minimum and the maximum fitted probabilities of truly being a smoker are reported. As detailed in the text, these provide a rough measure of identification of the false positive, $\alpha_{0}$, and false negative, $\alpha_{1}$, rates, respectively. NAs are reported for the standard error of $\alpha_{0}$ when it is estimated to be zero. This occurs as a result of constraining $\alpha_{0}$ to be nonnegative. 
Figure 1. Logit with and without Misclassification

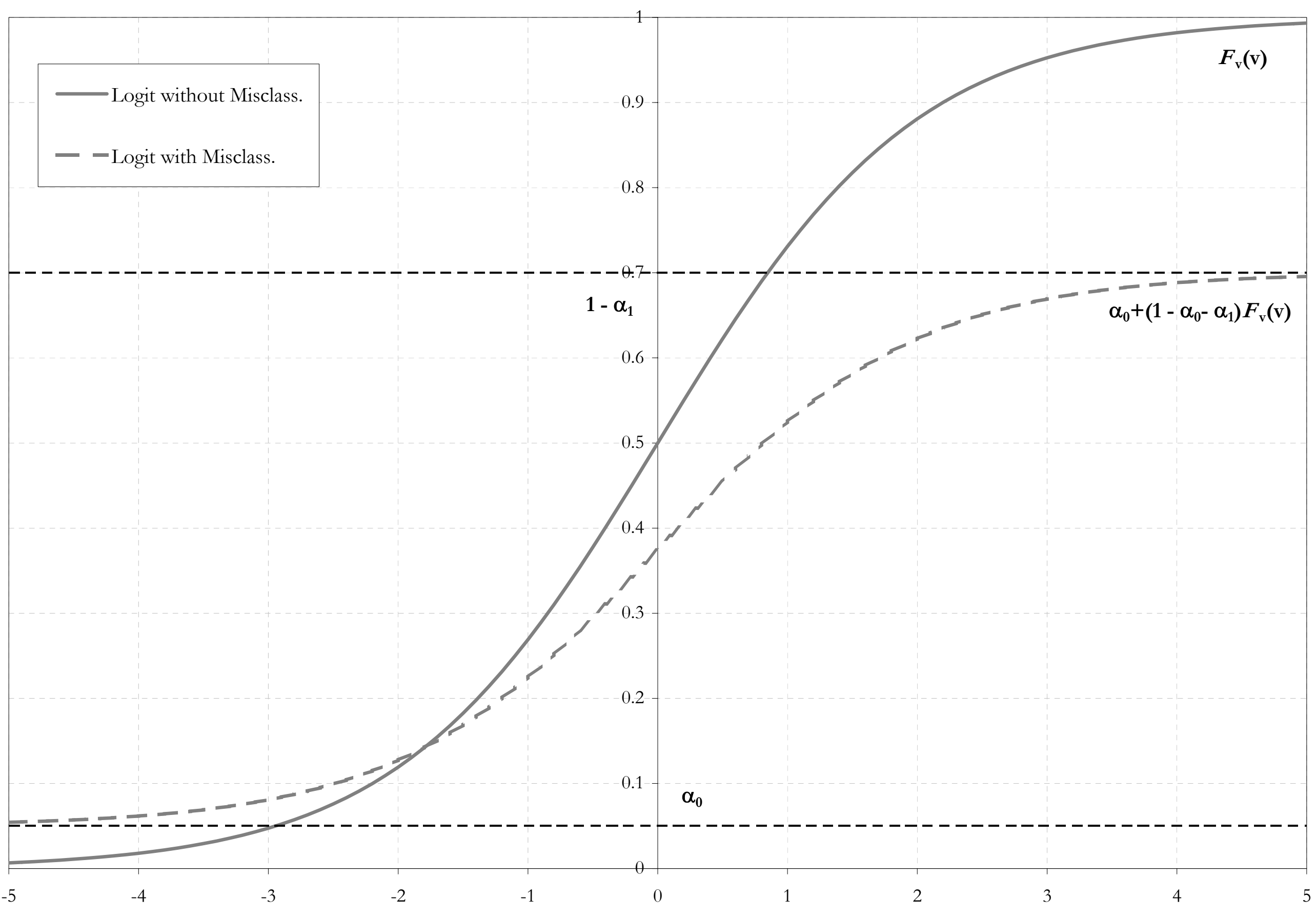


Figure 2 - Effect of False Negative Rate $\left(\alpha_{1}\right)$ on First Stage Estimates of Average Marginal Effect of Cigarette Taxes at Birthmonth on Smoking Participation

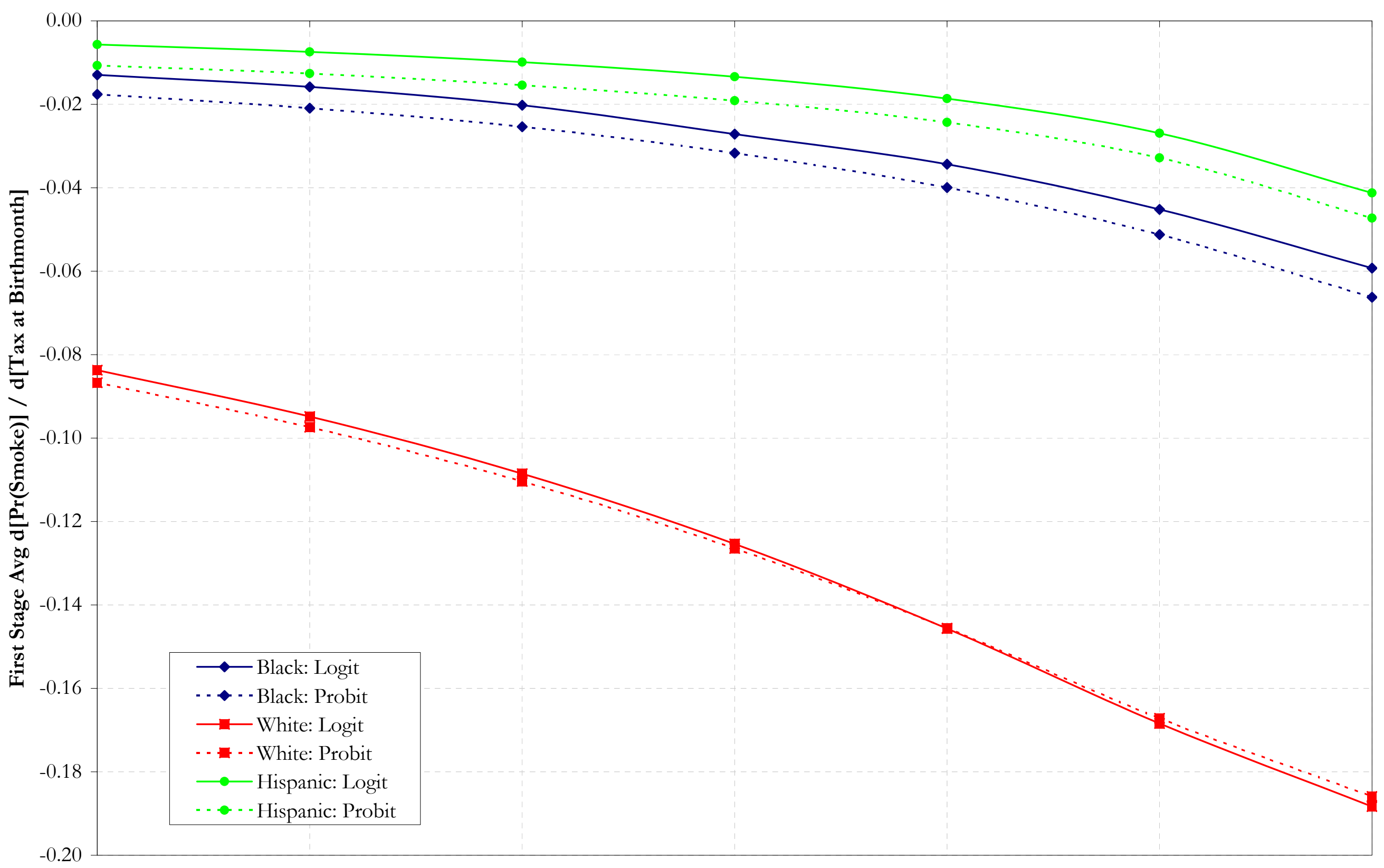

False Negative Rate: $\alpha_{1}=\operatorname{Pr}\left[S=0 \mid S^{*}=1\right]$ 
Figure 3 - Effect of False Negative Rate $\left(\alpha_{1}\right)$ on Second Stage Estimates of Effect of Maternal Smoking on Infant Birthweight

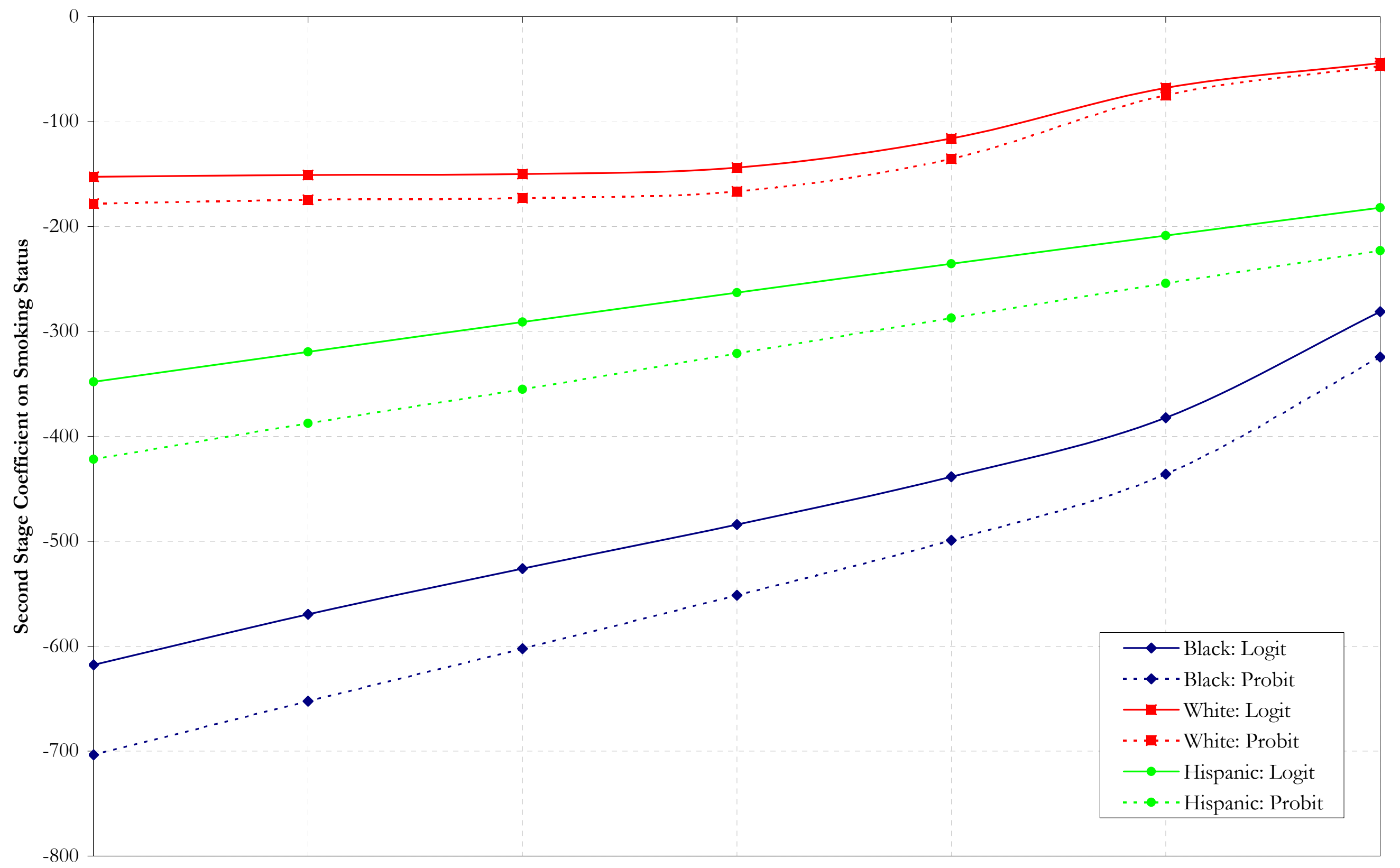

False Negative Rate: $\alpha_{1}=\operatorname{Pr}\left[S=0 \mid S^{*}=1\right]$ 
Figure 4 - Black vs. White Self-Reported Smoking Rates By State

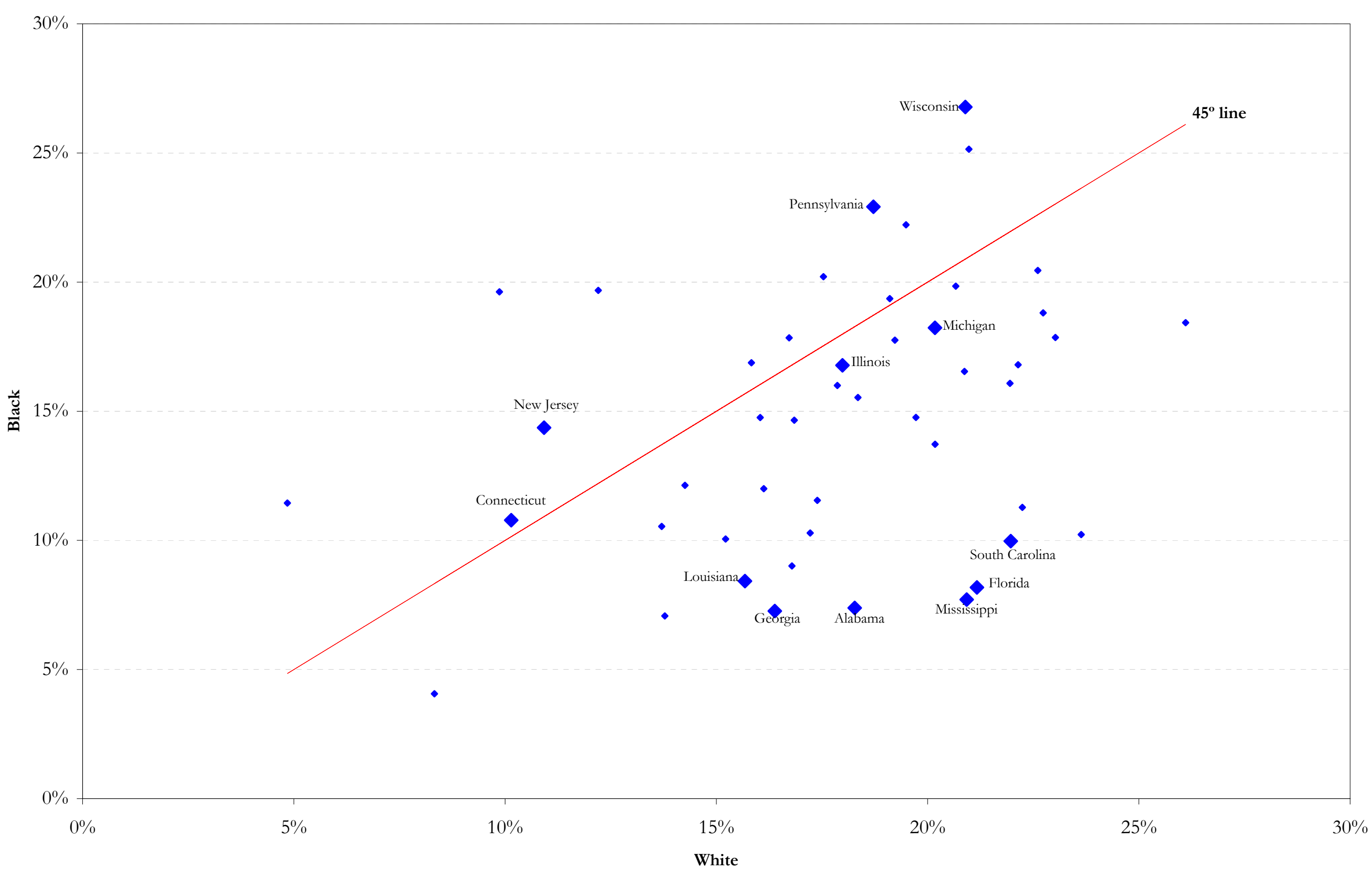

